Research Article

\title{
Serum Glycoproteomics and Identification of Potential Mechanisms Underlying Alzheimer's Disease
}

\author{
Naphatthakarn Kerdsaeng $\mathbb{D}^{1},{ }^{1}$ Sittiruk Roytrakul $\mathbb{D}^{2},{ }^{2}$ Suwannee Chanprasertyothin $\mathbb{D}^{3}{ }^{3}$ \\ Piangporn Charernwat $\mathbb{D}^{4}{ }^{4}$ Sirintorn Chansirikarnjana $\left(\mathbb{D},{ }^{4}\right.$ Piyamitr Sritara $\left(\mathbb{D},{ }^{4}\right.$ \\ and Jintana Sirivarasai $(\mathbb{D}$ \\ ${ }^{1}$ Doctor of Philosophy Programme in Molecular Medicine, Faculty of Science \& Faculty of Medicine Ramathibodi Hospital, \\ Faculty of Medicine Siriraj Hospital \& Faculty of Dentistry \& Faculty of Tropical Medicine, Mahidol University, \\ Bangkok, Thailand \\ ${ }^{2}$ Functional Ingredients and Food Innovation Research Group, National Center for Genetic Engineering and Biotechnology, \\ National Science and Technology Development Agency, Pathum Thani, Thailand \\ ${ }^{3}$ Research \& Innovation, Faculty of Medicine Ramathibodi Hospital, Mahidol University, Bangkok, Thailand \\ ${ }^{4}$ Department of Medicine, Faculty of Medicine Ramathibodi Hospital, Mahidol University, Bangkok, Thailand \\ ${ }^{5}$ Graduate Program in Nutrition, Faculty of Medicine Ramathibodi Hospital, Mahidol University, Bangkok, Thailand
}

Correspondence should be addressed to Jintana Sirivarasai; jintana.sir@mahidol.ac.th

Received 26 August 2021; Revised 4 November 2021; Accepted 16 November 2021; Published 11 December 2021

Academic Editor: Fabio M. Macciardi

Copyright (c) 2021 Naphatthakarn Kerdsaeng et al. This is an open access article distributed under the Creative Commons Attribution License, which permits unrestricted use, distribution, and reproduction in any medium, provided the original work is properly cited.

\begin{abstract}
Objectives. This study compares glycoproteomes in Thai Alzheimer's disease (AD) patients with those of cognitively normal individuals. Methods. Study participants included outpatients with clinically diagnosed AD $(N=136)$ and healthy controls without cognitive impairment $(N=183)$. Blood samples were collected from all participants for biochemical analysis and for Apolipoprotein E (APOE) genotyping by real-time TaqMan PCR assays. Comparative serum glycoproteomic profiling by liquid chromatography-tandem mass spectrometry was then performed to identify differentially abundant proteins with functional relevance. Results. Statistical differences in age, educational level, and $A P O E \varepsilon 3 / \varepsilon 4$ and $\varepsilon 4 / \varepsilon 4$ haplotype frequencies were found between the $\mathrm{AD}$ and control groups. The frequency of the $A P O E \varepsilon 4$ allele was significantly higher in the $\mathrm{AD}$ group than in the control group. In total, 871 glycoproteins were identified, including 266 and 259 unique proteins in control and AD groups, respectively. There were 49 and 297 upregulated and downregulated glycoproteins, respectively, in AD samples compared with the controls. Unique AD glycoproteins were associated with numerous pathways, including Alzheimer's disease-presenilin pathway (16.6\%), inflammation pathway mediated by chemokine and cytokine signaling (9.2\%), Wnt signaling pathway (8.2\%), and apoptosis signaling pathway (6.7\%). Conclusion. Functions and pathways associated with protein-protein interactions were identified in AD. Significant changes in these proteins can indicate the molecular mechanisms involved in the pathogenesis of $\mathrm{AD}$, and they have the potential to serve as $\mathrm{AD}$ biomarkers. Such findings could allow us to better understand $\mathrm{AD}$ pathology.
\end{abstract}

\section{Introduction}

Alzheimer's disease $(\mathrm{AD})$ or other forms of dementia have been reported in approximately 44 million people worldwide. $\mathrm{AD}$ is the most common cause of dementia, accounting for an estimated $60 \%$ to $80 \%$ of cases [1]. The population of Americans aged 65 and older is projected to grow from 56 million in 2020 to 88 million by 2050 [2]. The percentage of people with Alzheimer's dementia increases with age: $5.3 \%$ in people aged 65 to $74,13.8 \%$ in people aged 75 to 84 , and $34.6 \%$ in people aged 85 and older [3]. In China, the age-associated prevalence of $\mathrm{AD}$ is $3.2 \%$ in individuals over 60 years old, and it is predicted to increase from 3.8 to $6.2 \%$ in the next 5 years [4]. The prevalence of 
dementia in Thailand for people aged 45 years and above is $2.4 \%$ with $\mathrm{AD}$ being the most common type of dementia (75.0\%) [5]. AD involves many factors and incorporates many hypotheses. A large number of human studies and animal models have described many of these factors and hypotheses including amyloid $\beta(\mathrm{A} \beta)$, tau, cholinergic neuron damage, calcium dyshomeostasis and pathological calcium signaling, oxidative stress, inflammation, apoptotic signals, and other intracellular signaling pathways. ${ }^{6-8}$ Transgenic mice were used to identify precursors to plaque formation and how the aggregation of $\mathrm{A} \beta$ is crucial to its toxicity [6]. The amyloid cascade hypothesis predicts that tau hyperphosphorylation occurs as a downstream consequence of $\mathrm{A} \beta$ accumulation [6]. In addition, the mechanisms involved in beta-amyloid-mediated inflammation act as an immune stimulus for glial/macrophage activation. Using immunocytochemistry to examine numerous cytokines including interleukin- (IL-) 1alpha, IL-1beta, IL-6, tumor necrosis factor- (TNF-) alpha, and macrophage chemotactic protein(MCP-) 1, only IL-1beta was found to be induced in reactive astrocytes surrounding beta-amyloid deposits in 14-monthold transgenic Tg2576 mice [7]. A Taiwanese study compared amyloid beta peptide $42(\mathrm{~A} \beta 42)$ and tau levels in plasma samples using ultrasensitive immunomagnetic reduction assays, and they showed differences in plasma tau and $\mathrm{A} \beta 42$ levels. Levels of both proteins were higher in $\mathrm{AD}$ than in healthy, nondemented control subjects [8]. These findings and others support the use of plasma $\mathrm{A} \beta 42$ and tau as biomarkers in the clinical assessment of $\mathrm{AD}$ [8]. The underlying rationale of using core pathological proteins, including $\mathrm{A} \beta 42$, $\mathrm{A} \beta 40$, tau, tau phosphorylated at threonine-181 (Thr181P), inflammatory cytokines, oxidized proteins, and proteins in signaling pathways, has been widely stated. Proteomics is an emerging method for the identification of proteins, investigation of posttranslational modification, and determination of complex interactions of proteins in cellular systems (including their structure, function, and localization) [9]. Comprehensive proteomic analysis of human plasma or serum is a strategy used to identify biomarkers that underlie pathophysiology thereby promoting advances in diagnostic profiling, disease monitoring, and treatment [10]. Comprehensive quantitative analyses of proteins in $\mathrm{AD}$ and controls by high-resolution two-dimensional liquid chromatography and tandem mass spectrometry (LC/LC-MS/MS) identified differentially expressed proteins in $\mathrm{AD}$ (26 downregulated and 4 upregulated). These proteins were related to known pathways of mitochondrial dysfunction, fatty acid beta oxidation, and advanced glycation end products (AGEs) and their receptors (RAGEs) [11].

Glycoproteomics focuses on studying the profile of glycosylated proteins, and analysis involves tryptic glycopeptide enrichment following LC-MS/MS. Protein glycosylation is a complex posttranslational modification that is associated with the biological activity and function of glycoproteins [12]. Moreover, alterations in glycosylation profiles are associated with many diseases, including cancer, inflammation, and neurodegenerative diseases [13]. A glycoproteome profiling study characterizing protein $\mathrm{N}$-glycosylation in human $\mathrm{AD}$ and control brains produced significant findings. Multi- ple dysregulated n-glycosylation-affected processes and pathways were observed in an AD brain, including extracellular matrix dysfunction, neuroinflammation, synaptic dysfunction, cell adhesion alteration, lysosomal dysfunction, endocytic trafficking dysregulation, endoplasmic reticulum dysfunction, and cell signaling dysregulation [14].

However, analysis of glycosylation of AD-related proteins in serum or plasma remains to be fully explored. Here, we describe a glycoproteomic study comparing Thai AD patients with normally cognitive individuals. This study describes $\mathrm{AD}$ serum-enriched glycoproteins, which have the potential to be used as diagnostic and/or prognostic markers.

\section{Materials and Methods}

2.1. Study Design and Subjects. This study included outpatients with dementia due to $\mathrm{AD}$ and healthy controls without cognitive impairment, who were all fluent in Thai. A total of $136 \mathrm{AD}$ individuals (aged $\geq 65$ years) were recruited from the geriatric and psychiatry (memory) outpatient clinics, Faculty of Medicine Ramathibodi Hospital, Mahidol University, between 2011 and 2013. All patients were diagnosed by impairments in memory, thinking, and behavior, which decreased each person's ability to function independently in everyday life. Clinical assessments and biomarker evidences were carried out in some $\mathrm{AD}$ cases to provide additional diagnostic certainty. Such assessments included neuropsychological testing, specialized structural neuroimaging with magnetic resonance imaging (presence of medial temporal lobe atrophy), and cerebrospinal fluid analysis of tau/A-beta [15]. We further accessed medical records and contacted patients who were diagnosed with AD. The controls were participants from the Electricity Generating Authority of Thailand (EGAT) study conducted in 2013 ( $N=183$, age $\geq 55$ years) with normal cognitive function (evaluated by Montreal Cognitive Assessment (MoCA) $\geq 26$ ). Exclusion criteria included history of head injury, chronic metabolic diseases, severe auditory or visual sensory impairment, severe concurrent medical illness such as severe heart diseases and malignant tumors, or major psychiatric disorders such as major depression, bipolar disorder, and schizophrenia. Informed consent was obtained from all subjects, and all procedures for this study were approved by the Ethics Committee on Human Rights Related to Research Involving Human Subjects, Faculty of Medicine Ramathibodi Hospital, Mahidol University.

2.2. Biochemical Measurements. Venous blood samples were collected in the morning after an overnight fast (12 hours), and serum samples were separated and stored at $-80^{\circ} \mathrm{C}$ for subsequent analysis. Glycated hemoglobin (HbAlc), fasting blood glucose (FBG), total cholesterol, triglyceride (TG), high-density lipoprotein (HDL) cholesterol, low-density lipoprotein (LDL) cholesterol, total protein, albumin, urea nitrogen, and creatinine concentrations were measured using automated methods (Cobas-Mira, Roche, Milan, Italy). The levels of plasma folate and vitamin B12 were determined by electrochemiluminescence immunoassays (ECLIA). 
2.3. APOE Genotyping. Genomic DNA was extracted from whole blood in EDTA-coated tubes by a standard phenolchloroform extraction procedure and frozen at $-20^{\circ} \mathrm{C}$ until use. The DNA concentration was measured using a NanoDrop $2000^{\mathrm{TM}}$ Spectrophotometer (Thermo Fisher Scientific, Massachusetts, USA). The APOE single-nucleotide polymorphisms (SNPs) (rs429358 and rs7412) were genotyped using TaqMan ${ }^{\circledR}$ real-time polymerase chain reactions (real-time PCR). TaqMan SNP assays, designed by Applied Biosystems, are delivered as $20 \times$ or $40 \times$ single tube mixtures $(188 \mu \mathrm{L})$ of forward and reverse primers $(900 \mu \mathrm{M})$ and two reporter probes $(200 \mu \mathrm{M})$. The $5^{\prime}$ end of each probe is linked to different fluorescent allele-specific dyes: fluorescein amidite (FAM) is allele 2 specific, while VIC is the reporter for allele 1 . The $2 \times$ TaqMan universal PCR master mix (Applied Biosystems) used contains AmpliTaq Gold ${ }^{\circledR}$ DNA polymerase, dNTPs, and a passive internal reference based on proprietary ROX dye. To prepare the reaction mix to amplify 96 samples in a 96-well plate format, $15 \mu \mathrm{L}$ of $20 \times$ working stock of the SNP Genotyping Assay (or $7.5 \mu \mathrm{L}$ of $40 \times$ stock) was added to $285 \mu \mathrm{L}$ of $2 \times$ universal master mix diluted with $200 \mu \mathrm{L}$ of distilled water. After vortexing, $10 \mu \mathrm{L}$ of the mixture was transferred into each well of a 96 reaction plate before adding $20 \mathrm{ng}$ of wet genomic DNA. The plate was sealed and inserted into the One Step Applied Biosystems real-time PCR machine. PCR temperature was kept on hold for 10 minutes at $95^{\circ} \mathrm{C}$, then reduced to $92^{\circ} \mathrm{C}$ for 15 seconds (denaturation), and further reduced for annealing and extension stages to $60^{\circ} \mathrm{C}$ for 1 minute for 40 cycles.

2.4. Isolation of Glycoprotein from Serum Samples Using Concanavalin A. Protein concentration of serum samples was determined according to the Lowry protein assay using bovine serum albumin (BSA) as the standard [16]. Five hundred micrograms of protein from each sample was taken for glycoprotein enrichment using a Pierce glycoprotein isolation kit, ConA, and then desalted using the Zeba ${ }^{\mathrm{TM}}$ Desalt spin column according to the manufacturer's protocol. To reduce disulfide bond, $10 \mathrm{mM}$ dithiothreitol in $10 \mathrm{mM}$ ammonium bicarbonate was added to $5 \mu \mathrm{g}$ of purified glycoproteins, and reformation of disulfide bonds in the glycoproteins was blocked by alkylation with $30 \mathrm{mM}$ iodoacetamide in $10 \mathrm{mM}$ ammonium bicarbonate. The glycoprotein samples were digested with $200 \mathrm{ng}$ of sequencing grade porcine trypsin (Promega; Mannheim, Germany) for $12 \mathrm{~h}$ at $37^{\circ} \mathrm{C}$. The tryptic peptides were dried using a speed vacuum concentrator and kept at $-80^{\circ} \mathrm{C}$ for further mass spectrometric analysis.

2.5. Protein Quantitation and Identification by LC-MS/MS. Tryptic peptide samples were resuspended in $0.1 \%$ formic acid before injecting into an Ultimate 3000 Nano/Capillary LC System (Thermo Scientific, UK) coupled to a Hybrid quadrupole Q-TOF impact II ${ }^{\mathrm{TM}}$ (Bruker Daltonics) equipped with a nanocaptive spray ion source. Briefly, peptides were enriched on a $\mu$-precolumn $(300 \mu \mathrm{m}$ i.d. $\times 5 \mathrm{~mm}$ with $\mathrm{C} 18$ PepMap 100, $5 \mu \mathrm{m}, 100 \mathrm{~A}$, Thermo Scientific, UK) and separated on a $75 \mu \mathrm{m}$ I.D. $\times 15 \mathrm{~cm}$ column packed with Acclaim PepMap RSLC C18 $(2 \mu \mathrm{m}, 100 \AA$, nanoViper, Thermo Scientific, UK). Solvent A and B contain $0.1 \%$ formic acid in water and $0.1 \%$ formic acid in $80 \%$ acetonitrile, respectively. A gradient of $5-55 \%$ solvent B was used to elute the peptides at a constant flow rate of $0.30 \mu \mathrm{L} / \mathrm{min}$ for $30 \mathrm{~min}$. Electrospray ionization was carried out at $1.6 \mathrm{kV}$ using the CaptiveSpray. Mass spectra (MS) and MS/MS spectra were obtained in the positive-ion mode over the range $(\mathrm{m} / \mathrm{z})$ 150-2200 (Compass 1.9 software, Bruker Daltonics). The LC-MS analysis of each sample was done in triplicate.

MaxQuant 1.6.1.12 was used to quantify the proteins in individual samples using the Andromeda search engine to correlate MS/MS spectra with the UniProt Homo sapiens database [16]. The following parameters were used for data processing: maximum of two miss cleavages, mass tolerance of $20 \mathrm{ppm}$ for the main search, trypsin as the digesting enzyme, carbamidomethylation of cysteines as fixed modification, and the oxidation of methionine and acetylation of the protein $\mathrm{N}$-terminus as variable modifications. Only peptides with a minimum of seven amino acids, as well as at least one unique peptide, were required for protein identification. Only proteins with at least two peptides, and at least one unique peptide, were considered being identified and used for further data analysis.

All differentially expressed proteins were analyzed for their intersections among the different sample groups using jvenn [17]. Gene Ontology annotation, including biological process, cellular component, and molecular function, was performed using Panther (http://www.pantherdb.org). The identified proteins were simultaneously submitted to the Search Tool for Interacting Chemicals (STITCH) (http:// stitch.embl.de) to search for understanding of cellular functions and interactions between proteins and small molecules.

2.6. Statistical Analysis. All statistical analyses were performed with SPSS Statistics for Windows, version 22.0 (IBM SPSS Statistics for Windows, version 23.0. Armonk, NY: IBM Corp). Data are presented as the mean \pm standard deviation. Allele and genotype differences between groups and deviations from the Hardy-Weinberg equilibrium were tested by chi-square tests.

\section{Results}

3.1. Demographic and Clinical Characteristics of Participants. The control group consisted of healthy individuals with normal cognitive function (with a mean age of $56.52 \pm 4.13$ years; more than $60 \%$ were female (Table 1)). A normal Montreal Cognitive Assessment (MoCA) score is considered to be $\geq 26$. The mean MoCA of the control group was 28.20 , and $86.9 \%$ of participants had $>12$ years of education. Biochemical analysis related to glycemic parameters, lipid profile, kidney, and thyroid functions was in the reference ranges. For the $\mathrm{AD}$ group, the mean age was $78.08 \pm 7.47$ years; $77.95 \%$ were female $(n=136)$ and $58.1 \%$ have educational level $\leq 12$ years, as shown in Table 2. Most patients reported no family history of $\mathrm{AD}$, and their diagnoses were confirmed by physicians in the geriatric and psychiatry (memory) outpatient clinic. Similar to the control 
TABLE 1: Characteristics and clinical parameters of the controls (normal cognitive function) and the $\mathrm{AD}$ group.

\begin{tabular}{|c|c|c|}
\hline Characteristics & $\begin{array}{l}\text { Normal cognitive } \\
\text { function } \\
(N=183) \\
\end{array}$ & $\begin{array}{c}\text { Alzheimer's } \\
\text { disease (AD) } \\
(N=136)\end{array}$ \\
\hline Age, years & $56.52 \pm 4.13$ & $78.08 \pm 7.47^{*}$ \\
\hline \multicolumn{3}{|l|}{ Gender } \\
\hline Male & $50(27.3)$ & $30(22.1)$ \\
\hline Female & $133(72.7)$ & $106(77.9)$ \\
\hline $\begin{array}{l}\text { Body mass index (BMI) } \\
\left(\mathrm{kg} / \mathrm{m}^{2}\right)\end{array}$ & $24.82 \pm 3.41$ & $22.91 \pm 3.24$ \\
\hline \multicolumn{3}{|l|}{ Blood pressure $(\mathrm{mmHg})$} \\
\hline Systolic blood pressure & $124.65 \pm 9.85$ & $110.39 \pm 7.89$ \\
\hline $\begin{array}{l}\text { Diastolic blood } \\
\text { pressure }\end{array}$ & $80.92 \pm 9.88$ & $77.45 \pm 10.23$ \\
\hline \multicolumn{3}{|l|}{ Educational level } \\
\hline$\leq 12$ years & $24(13.1 \%)$ & $79(58.1)^{*}$ \\
\hline$>12$ years & $159(86.9 \%)$ & $57(41.9)$ \\
\hline FBG $(\mathrm{mg} / \mathrm{dL})$ & $102.48 \pm 28.42$ & $102.5 \pm 36.7$ \\
\hline Total cholesterol (mg/dL) & $202.00 \pm 36.45$ & $186.74 \pm 40.15$ \\
\hline LDL-cholesterol (mg/dL) & $132.24 \pm 42.12$ & $115.61 \pm 36.42$ \\
\hline HDL-cholesterol (mg/dL) & $54.75 \pm 17.14$ & $48.71 \pm 11.82$ \\
\hline Triglyceride (mg/dL) & $136.56 \pm 52.45$ & $117.30 \pm 66.61$ \\
\hline Albumin (mg/dL) & $4.72 \pm 0.24$ & $3.79 \pm 0.41$ \\
\hline $\mathrm{Hb}(\mathrm{g} / \mathrm{dL})$ & $14.34 \pm 1.48$ & $12.84 \pm 1.27$ \\
\hline Hct $(\%)$ & $42.27 \pm 3.88$ & $38.95 \pm 4.21$ \\
\hline Folate $(\mathrm{ng} / \mathrm{mL})$ & $10.47 \pm 5.20$ & $16.43 \pm 11.02$ \\
\hline Vitamin B12 $(\mu \mathrm{g} / \mathrm{L})$ & $665.10 \pm 125.69$ & $824.21 \pm 229.73$ \\
\hline
\end{tabular}

${ }^{*}$ Significant difference at $P<0.05$.

TABLE 2: Frequency distribution of haplotypes and alleles of APOE.

\begin{tabular}{|c|c|c|}
\hline & Control group $(N=183)$ & $\operatorname{AD}$ group $(N=136)$ \\
\hline \multicolumn{3}{|c|}{$\begin{array}{l}\text { APOE } \\
\text { haplotypes }\end{array}$} \\
\hline$\varepsilon 2 / \varepsilon 2$ & $2(1.1 \%)$ & - \\
\hline$\varepsilon 2 / \varepsilon 3$ & $31(16.9 \%)$ & $10(7.4 \%)$ \\
\hline$\varepsilon 3 / \varepsilon 3$ & $111(60.7 \%)$ & $64(47.1 \%)$ \\
\hline$\varepsilon 2 / \varepsilon 4$ & $9(4.9 \%)$ & $4(2.9 \%)$ \\
\hline$\varepsilon 3 / \varepsilon 4$ & $28(15.3 \%)$ & $44(32.4 \%)^{\mathrm{a}}$ \\
\hline$\varepsilon 4 / \varepsilon 4$ & $2(1.1 \%)$ & $14(10.3 \%)^{\mathrm{a}}$ \\
\hline \multicolumn{3}{|c|}{ Allele frequencies } \\
\hline$\varepsilon 2$ & 0.12 & 0.07 \\
\hline$\varepsilon 3$ & 0.77 & $0.47^{\mathrm{a}}$ \\
\hline$\varepsilon 4$ & 0.11 & $0.46^{\mathrm{a}}$ \\
\hline
\end{tabular}

${ }^{\mathrm{a}} P$ value $<0.01$ compared between controls and $\mathrm{AD}$ groups.

group, blood biochemistry tests in the $\mathrm{AD}$ group were in normal ranges.

3.2. Distributions of APOE Haplotypes and Alleles in Control and $A D$ Groups. Six and five APOE haplotypes were detected in the control and the $\mathrm{AD}$ groups, respectively. The most common $A P O E$ haplotypes in the control and $\mathrm{AD}$ groups was $\varepsilon 3 / \varepsilon 3$. The $\varepsilon 2 / \varepsilon 2$ was a haplotype not found in the $\mathrm{AD}$ group (Table 3). Statistical differences in APOE $\varepsilon 3 / \varepsilon 4$ and $\varepsilon 4 / \varepsilon 4$ haplotype frequencies were found between both groups. The frequency of the $\varepsilon 4$ allele was significantly higher in the $\mathrm{AD}$ group than in the control group, whereas the $\varepsilon 3$ allele frequency was significantly higher in the control group than in the AD group $(P<0.05)$.

3.3. Proteomic Analysis. Proteomic analysis of serum protein patterns in control and $\mathrm{AD}$ groups are described in Tables 1-6 and Figures 1 and 2. Approximately 600 proteins from each of the control and $\mathrm{AD}$ groups were identified at a false discovery rate of $1 \%$. Comparative proteomic analysis was performed between sera of the two groups with 42 upregulated glycoproteins in Table 3 and 287 downregulated glycoproteins in Table 4 (for all proteins in this group, see Supplementary Table 1). Table 5 shows the classification of upregulated proteins as follows: protein-binding activity modulator (16.7\%), gene-specific transcriptional regulator (12.5\%), metabolite interconversion enzyme (12.5\%), and others. Moreover, categories with the highest percentages of downregulated proteins were interconversion enzymes (13.7\%), protein-modifying enzymes (12.4\%), proteins used in nucleic acid metabolism (12.4\%), and others (Table 5). Further analysis using the Universal Protein Resource (UniProt) identified the top five upregulated glycoproteins including A disintegrin and metalloproteinase with thrombospondin motifs 8 (ADAMTS8), ubiquitin-fold modifier-conjugating enzyme 1 (UFC1), kinesin-like protein KIF28P (KIF28P), protein Ras-related protein Rab-6A (RAB6A), and coagulation factor X (FX). The top five downregulated glycoproteins were C-type mannose receptor 2 (MRC2), FAS-associated factor 2 (FAF2), NAD-dependent protein lipoamidase sirtuin4 (mitochondrial; SIRT4), ankyrin repeat domain-containing protein 13C (ANKRD13C), and brain-specific angiogenesis inhibitor 1-associated protein 2-like protein 1 (BAIAP2L1).

In total, 871 glycoproteins were identified, including 266 and 259 unique proteins in control and AD groups, respectively, as represented by a jvenn diagram (Figure 1). Further analysis was performed on the unique glycoproteins in $\mathrm{AD}$ patients. The classification and pathways of the identified glycoproteins were analyzed by the UniProt tool and PANTHER-gene list analysis (Table 6). According to molecular function, glycoproteins were classified as organic cyclic compound binding (26.0\%), heterocyclic compound binding (26.0\%), protein binding (24.7\%), ion binding (5.5\%), small molecule binding (5.5\%), and carbohydrate binding (5.6\%). For biological process, these glycoproteins were categorized as cellular process $(32.3 \%)$, metabolic process $(15.5 \%)$, biological regulation (15.1\%), and others. In addition, relevant pathways were identified as Alzheimer disease-presenilin pathway (16.6\%), inflammation pathway mediated by chemokine and cytokine signaling (9.2\%), Wnt signaling pathway $(5.1 \%)$, and apoptosis signaling pathway $(5.1 \%)$, as described in Table 6.

Pathway analysis of the differentially expressed proteins in the $\mathrm{AD}$ group was performed using the STITCH database, 
TABLE 3: Upregulated glycoproteins in the serum of the $\mathrm{AD}$ group (identified proteins from the UniProt Homo sapiens database).

\begin{tabular}{|c|c|c|c|c|}
\hline Protein ID & Protein name & Mass & Glycosylation & Posttranslational modification \\
\hline Q9UP79 & $\begin{array}{l}\text { A disintegrin and metalloproteinase with } \\
\text { thrombospondin motifs 8 (ADAM-TS 8) } \\
\text { (ADAM-TS8) (ADAMTS-8) (EC 3.4.24.-) } \\
\text { (METH-2) (METH-8) }\end{array}$ & 96,460 & $\begin{array}{l}\text { N-linked } \\
\text { (GlcNAc) } \\
\text { asparagine }\end{array}$ & $\begin{array}{c}\text { PTM: the precursor is cleaved by a furin } \\
\text { endopeptidase }\end{array}$ \\
\hline B7ZC32 & $\begin{array}{l}\text { Kinesin-like protein KIF28P } \\
\text { (kinesin-like protein 6) }\end{array}$ & 108,254 & & \\
\hline Q9Y3C8 & $\begin{array}{l}\text { Ubiquitin-fold modifier-conjugating enzyme } 1 \\
\text { (Ufm1-conjugating enzyme 1) }\end{array}$ & 19,458 & & \\
\hline P00742 & $\begin{array}{c}\text { Coagulation factor X (EC 3.4.21.6) (Stuart factor) } \\
\text { (Stuart-Prower factor) (cleaved into factor X light } \\
\text { chain, factor X heavy chain, and activated factor } \\
\text { Xa heavy chain) }\end{array}$ & 54,732 & $\begin{array}{l}\text { O-linked } \\
\text { (GalNAc) } \\
\text { threonine }\end{array}$ & $\begin{array}{l}\text { PTM: the vitamin K-dependent, enzymatic } \\
\text { carboxylation of some glutamate residues } \\
\text { allows the modified protein to bind to calcium }\end{array}$ \\
\hline P20340 & Ras-related protein Rab-6A (Rab-6) & 23,593 & & PTM: prenylated \\
\hline Q9NRR8 & $\begin{array}{l}\text { CDC42 small effector protein } 1 \\
\text { (CDC42-binding protein SCIP1) } \\
\text { (small effector of CDC42 protein } 1 \text { ) }\end{array}$ & 8,925 & & \\
\hline Q9NYH9 & $\begin{array}{l}\text { U3 small nucleolar RNA-associated protein } 6 \\
\text { homolog (hepatocellular carcinoma-associated } \\
\text { antigen 66) (multiple hat domain protein) }\end{array}$ & 70,194 & & \\
\hline P18077 & $\begin{array}{l}60 S \text { ribosomal protein L35a } \\
\text { (cell growth-inhibiting gene } 33 \text { protein) } \\
\text { (large ribosomal subunit protein eL33) }\end{array}$ & 12,538 & & \\
\hline Q3SXY7 & $\begin{array}{c}\text { Leucine-rich repeat, immunoglobulin-like } \\
\text { domain, and transmembrane domain-containing } \\
\text { protein } 3\end{array}$ & 74,754 & $\begin{array}{l}\text { N-linked } \\
\text { (GlcNAc) } \\
\text { asparagine }\end{array}$ & PTM: glycosylated \\
\hline Q9NUL5 & $\begin{array}{l}\text { Shiftless antiviral inhibitor of ribosomal } \\
\text { frameshifting protein (SFL) (SHFL) } \\
\text { (interferon-regulated antiviral protein) (IRAV) } \\
\text { (repressor of yield of DENV protein) (RyDEN) }\end{array}$ & 33,110 & & \\
\hline Q12788 & $\begin{array}{c}\text { Transducin beta-like protein } 3 \\
\text { (WD repeat-containing protein SAZD) }\end{array}$ & 89,035 & & \\
\hline O94854 & Uncharacterized protein KIAA0754 & 135,148 & & \\
\hline Q9BXJ7 & $\begin{array}{c}\text { Protein amnionless (cleaved into soluble } \\
\text { protein amnionless) }\end{array}$ & 47,754 & $\begin{array}{l}\text { N-linked } \\
\text { (GlcNAc) } \\
\text { asparagine }\end{array}$ & PTM: N-glycosylated \\
\hline Q09019 & $\begin{array}{c}\text { Dystrophia myotonica WD repeat-containing } \\
\text { protein (Dystrophia myotonica-containing } \\
\text { WD repeat motif protein) (protein 59) } \\
\text { (protein DMR-N9) }\end{array}$ & 70,438 & & \\
\hline Q02846 & $\begin{array}{c}\text { Retinal guanylyl cyclase } 1 \text { (RETGC-1) (EC } \\
\text { 4.6.1.2) (CG-E) (guanylate cyclase } 2 \mathrm{D} \text {, retinal) } \\
\text { (rod outer segment membrane guanylate cyclase) } \\
\text { (ROS-GC) }\end{array}$ & 120,059 & $\begin{array}{l}\text { N-linked } \\
\text { (GlcNAc) } \\
\text { asparagine }\end{array}$ & \\
\hline Q3LHN2 & Keratin-associated protein $19-2$ & 5,737 & & \\
\hline O95925 & $\begin{array}{c}\text { Eppin (cancer/testis antigen 71) (CT71) } \\
\text { (epididymal protease inhibitor) (protease } \\
\text { inhibitor WAP7) (serine protease inhibitor-like } \\
\text { with Kunitz and WAP domain 1) } \\
\text { (WAP four-disulfide core domain protein 7) }\end{array}$ & 15,284 & & \\
\hline Q9NYW3 & $\begin{array}{l}\text { Taste receptor type } 2 \text { member } 7 \text { (T2R7) } \\
\text { (taste receptor family B member } 4 \text { ) (TRB4) }\end{array}$ & 36,550 & $\begin{array}{l}\text { N-linked } \\
\text { (GlcNAc) } \\
\text { asparagine }\end{array}$ & \\
\hline Q6UWV2 & Myelin protein zero-like protein 3 & 25,989 & $\begin{array}{l}\text { N-linked } \\
\text { (GlcNAc) } \\
\text { asparagine }\end{array}$ & \\
\hline
\end{tabular}


TABle 3: Continued.

\begin{tabular}{|c|c|c|c|c|}
\hline Protein ID & Protein name & Mass & Glycosylation & Posttranslational modification \\
\hline Q9Y5X4 & $\begin{array}{c}\text { Photoreceptor-specific nuclear receptor } \\
\text { (nuclear receptor subfamily } 2 \text { group E member } 3 \text { ) } \\
\text { (retina-specific nuclear receptor) }\end{array}$ & 44,692 & & \\
\hline Q6Y288 & $\begin{array}{l}\text { Beta-1,3-glucosyltransferase (Beta3Glc-T) } \\
\text { (EC 2.4.1.-) (beta 3-glucosyltransferase) } \\
\text { (beta-3-glycosyltransferase-like) }\end{array}$ & 56,564 & $\begin{array}{l}\text { N-linked } \\
\text { (GlcNAc) } \\
\text { asparagine }\end{array}$ & \\
\hline Q8TB45 & $\begin{array}{l}\text { DEP domain-containing mTOR-interacting } \\
\text { protein (DEP domain-containing protein 6) }\end{array}$ & 46,294 & & $\begin{array}{l}\text { PTM: phosphorylated. Phosphorylation } \\
\text { weakens interaction with MTOR within } \\
\text { mTORC1 and mTORC2 }\end{array}$ \\
\hline Q9UPG8 & $\begin{array}{l}\text { Zinc finger protein PLAGL2 (pleiomorphic } \\
\text { adenoma-like protein 2) }\end{array}$ & 54,584 & & \\
\hline Q9HCG1 & $\begin{array}{l}\text { Zinc finger protein } 160 \text { (zinc finger protein } \\
\text { HZF5) (zinc finger protein Kr18) (HKr18) }\end{array}$ & 94,112 & & \\
\hline P30281 & G1/S-specific cyclin-D3 & 32,520 & & $\begin{array}{l}\text { PTM: polyubiquitinated by the SCF(FBXL2) } \\
\text { complex, leading to proteasomal degradation }\end{array}$ \\
\hline A0A286YF01 & $\begin{array}{l}\text { Small cysteine and glycine repeat-containing } \\
\text { protein } 7 \text { (keratin-associated protein } 28-7 \text { ) }\end{array}$ & 8,951 & & \\
\hline O15539 & Regulator of G protein signaling 5 (RGS5) & 20,946 & & \\
\hline Q12979 & Active breakpoint cluster region-related protein & 97,598 & & \\
\hline Q96EN8 & $\begin{array}{l}\text { Molybdenum cofactor sulfurase (MCS) (MOS) } \\
\text { (MoCo sulfurase) (hMCS) (EC 2.8.1.9) } \\
\text { (molybdenum cofactor sulfurtransferase) }\end{array}$ & 98,120 & & \\
\hline P13765 & $\begin{array}{l}\text { HLA class II histocompatibility antigen, DO beta } \\
\text { chain (MHC class II antigen DOB) }\end{array}$ & 30,822 & $\begin{array}{l}\text { N-linked } \\
\text { (GlcNAc } \\
\text { asparagine }\end{array}$ & \\
\hline Q6L8H2 & $\begin{array}{l}\text { Keratin-associated protein 5-3 (keratin- } \\
\text { associated protein 5-9) (keratin-associated } \\
\text { protein 5.3) (keratin-associated protein 5.9) } \\
\text { (UHS KerB-like) (ultrahigh sulfur } \\
\text { keratin-associated protein 5.3) }\end{array}$ & 22,106 & & \\
\hline P21941 & Cartilage matrix protein (Matrilin-1) & 53,701 & $\begin{array}{l}\text { N-linked } \\
\text { (GlcNAc) } \\
\text { asparagine }\end{array}$ & \\
\hline Q6IFN5 & $\begin{array}{l}\text { Olfactory receptor 7E24 (olfactory receptor } \\
\text { OR19-14) }\end{array}$ & 38,279 & $\begin{array}{l}\text { N-linked } \\
\text { (GlcNAc) } \\
\text { asparagine }\end{array}$ & \\
\hline Q96BH3 & $\begin{array}{l}\text { Epididymal sperm-binding protein } 1 \text { (epididymal } \\
\text { secretory protein } 12)(\mathrm{hE} 12)\end{array}$ & 26,106 & $\begin{array}{l}\text { N-linked } \\
\text { (GlcNAc) } \\
\text { asparagine }\end{array}$ & PTM: N-glycosylated \\
\hline O95149 & Snurportin-1 (RNA U transporter 1) & 41,143 & & \\
\hline Q9BSJ5 & $\begin{array}{l}\text { Uncharacterized protein C17orf } 80 \text { (cell } \\
\text { migration-inducing gene } 3 \text { protein) (human lung } \\
\text { cancer oncogene } 8 \text { protein) (HLC-8) }\end{array}$ & 67,315 & & \\
\hline Q9H1E5 & $\begin{array}{l}\text { Thioredoxin-related transmembrane protein } 4 \\
\text { (thioredoxin domain-containing protein 13) }\end{array}$ & 38,952 & & \\
\hline Q8NCL4 & $\begin{array}{c}\text { Polypeptide N-acetylgalactosaminyltransferase } 6 \\
\text { (EC 2.4.1.41) (polypeptide GalNAc transferase 6) } \\
\text { (GalNAc-T6) (pp-GaNTase 6) (protein-UDP } \\
\text { acetylgalactosaminyltransferase 6) (UDP- } \\
\text { GalNAc:polypeptide N-acetylgalacto } \\
\text { saminyltransferase 6) }\end{array}$ & 71,159 & $\begin{array}{l}\text { N-linked } \\
\text { (GlcNAc) } \\
\text { asparagine }\end{array}$ & \\
\hline Q4G112 & $\begin{array}{c}\text { Heat shock factor protein } 5 \text { (HSF 5) (heat shock } \\
\text { transcription factor 5) (HSTF 5) }\end{array}$ & 65,278 & & \\
\hline
\end{tabular}


TABLE 3: Continued.

\begin{tabular}{|c|c|c|c|c|}
\hline Protein ID & Protein name & Mass & Glycosylation & Posttranslational modification \\
\hline Q9Y6L6 & $\begin{array}{l}\text { Solute carrier organic anion transporter family } \\
\text { member 1B1 (liver-specific organic anion } \\
\text { transporter 1) (LST-1) (OATP-C) } \\
\text { (sodium-independent organic } \\
\text { anion-transporting polypeptide 2) (OATP-2) } \\
\text { (solute carrier family } 21 \text { member } 6)\end{array}$ & 76,449 & $\begin{array}{l}\mathrm{N} \text {-linked } \\
(\text { GlcNAc) } \\
\text { asparagine }\end{array}$ & \\
\hline P55073 & $\begin{array}{c}\text { Thyroxine 5-deiodinase (EC 1.21.99.3) } \\
\text { (5DIII) (DIOIII) (type } 3 \mathrm{DI}) \\
\text { (type III iodothyronine deiodinase) }\end{array}$ & 33,947 & & \\
\hline Q9H694 & Protein bicaudal C homolog 1 (Bic-C) & 104,844 & & \\
\hline
\end{tabular}

and the generated protein-protein network is presented in Figure 2. The network indicated interactions among members of the 45 unique glycoproteins identified in the $\mathrm{AD}$ group with pivotal proteins in pathogenesis and prevention of AD including APP, MAPT, tau protein, PSEN1, PSEN2, and APOE. An interaction network comprising 346 interactions was generated. These interactions were ascribed to Gene Ontology biological processes, including necroptic process, activation of cysteine-type endopeptidase activity involved in apoptotic signal pathway, positive regulation of catalytic activity, proteolysis, and I-kappaB kinase/NF-kappaB signaling, and to Kyoto Encyclopedia of Genes and Genomes (KEGG) pathways including apoptosis, AD pathways, and TNF signaling pathways.

\section{Discussion}

A decline in cognitive function is partly predisposed by increasing age as seen in the prevalence of $\mathrm{AD}$ or other dementias worldwide $[1,2,4]$, which is congruent with our findings. Proposed hypotheses involve age-related protein abnormalities and pinpointed protein dyshomeostasis in the aging brain $[18,19]$. Our findings also indicate a correlation between low education and a high risk of $\mathrm{AD}$ dementia, which coincides with a previous meta-analysis study that found a higher incidence of dementia in people with a lower level of education [20]. A plausible explanation for the effect of education on the clinical expression rather than the pathologic course of AD or dementia has been postulated [21].

The possible pathophysiological mechanisms related to $\mathrm{AD}$ in the Thai population were investigated by considering glycoproteomes and APOE gene data. Multiple genetic and environmental risk factors are involved in $\mathrm{AD}$ pathogenesis. Findings from previous studies support a role for genetic determinants in $\mathrm{AD}$ in $90 \%$ of early-onset $\mathrm{AD}$ (EOAD) cases and $58-79 \%$ of late-onset AD (LOAD) cases [22]. Genetic polymorphism in $A P O E$ is the main genetic risk factor in $\mathrm{LOAD}$, with increased risk of $\mathrm{AD}$ for carriers of the $\varepsilon 4$ allele, whereas the $\varepsilon 2$ allele conferred a decreased risk [23]. Significantly higher haplotypes and allele frequencies for $\varepsilon 4$ heterozygotes (APOE $\varepsilon 3 / \varepsilon 4)$ and $\varepsilon 4$ homozygotes (APOE $\varepsilon 4 / \varepsilon 4)$ were found in the $\mathrm{AD}$ group compared with the control group (Table 3). The prevalence of APOE $\varepsilon 4$ carriers $(42.7 \%)$ was in agreement with that for Asia (40.6\%), but lower than those for Southern Europe (44.1\%), Central
Europe (54.8\%), North America (58.5\%), Northern Europe (64.8\%) [23], and South America (54.8\%) [24]. The effects of $A P O E \& 4$ on $\mathrm{AD}$ risk have been proposed to include the following: inhibition of $\mathrm{A} \beta$ clearance and promotion of $\mathrm{A} \beta$ aggregation, tau pathology and tau-mediated neurodegeneration, impairment of microglia-inflammation response, disturbance of lipid transport, loss of synaptic integrity and plasticity, abnormal glucose metabolism, and disruption of cerebrovascular integrity and function [25].

The final form of a gene product is the synthesized protein; therefore, the proteome is directly related to biological function and is responsive to physiological states and diseases. Several quantitative proteomic studies in $\mathrm{AD}$ have been carried out on patient-derived biological samples including the brain, cerebrospinal fluid (CSF), and plasma. Both brain and CSF samples are known as the representative biomarkers for neurodegenerative analysis because their changes directly reflect brain pathophysiology, neuronal damage, and disease progression [26, 27]. However, brain tissue and CSF biomarker are not practical for the next step of biomarker discovery since validation methods involve a large number of cases and different disease stages. Serumbased proteomic biomarkers provide several advantages including the following: (1) it is a more practical approach with identification of numerous proteins from all tissues, (2) it is inexpensive, and (3) it provides a more effective tool for future research and clinical diagnosis since it implements only a blood test [10].

To better elucidate mechanisms underlying AD, we investigated alterations in serum glycoproteins. Our results show both upregulated and downregulated glycoproteins in AD sera compared with control sera. A disintegrin and metalloproteinase with thrombospondin motifs 8 (ADAMTS8) was upregulated in AD patients. ADAMTS8 is an ADAMTS member, a unique family of the extracellular matrix (ECM) proteases found in mammals. These glycoproteins are involved in neuroplasticity and the development of chronic neurodegenerative disorders, including AD [25]. The possible functions of ADAMTS proteases in AD might be linked to Reelin, a glycoprotein essential for brain development and function [28]. Decreased Reelin activity after ADAMTS digestion may lead to amyloid- $\beta$ deposition, Tau phosphorylation, and tangle formation in the hippocampal formation through disturbance of phosphatidylinositol-3-kinase (PI3K), protein kinase $\mathrm{B}(\mathrm{PKB} / \mathrm{Akt})$, and glycogen synthase kinase $3 \beta$ (GSK3 $\beta)$ 
TABLE 4: Downregulated glycoproteins in the serum of the AD group (identified proteins from the UniProt Homo sapiens database).

\begin{tabular}{|c|c|c|c|c|}
\hline $\begin{array}{l}\text { Protein } \\
\text { ID }\end{array}$ & Protein names & Mass & Glycosylation & Posttranslational modification \\
\hline Q9UBG0 & $\begin{array}{c}\text { C-type mannose receptor } 2 \text { (C-type lectin domain family } \\
13 \text { member E) (endocytic receptor 180) (macrophage } \\
\text { mannose receptor 2) (urokinase-type plasminogen } \\
\text { activator receptor-associated protein) (UPAR-associated } \\
\text { protein) (urokinase receptor-associated protein) } \\
\text { (CD antigen CD280) }\end{array}$ & 166,674 & $\begin{array}{l}\text { N-linked } \\
\text { (GlcNAc) } \\
\text { (complex) } \\
\text { asparagine }\end{array}$ & \multirow{18}{*}{$\begin{array}{l}\text { PTM: Phosphorylated on tyrosine in } \\
\text { response to insulin }\end{array}$} \\
\hline Q96CS3 & $\begin{array}{l}\text { FAS-associated factor } 2 \text { (protein ETEA) } \\
\text { (UBX domain-containing protein 3B) } \\
\text { (UBX domain-containing protein } 8 \text { ) }\end{array}$ & 52,623 & & \\
\hline Q9Y6E7 & $\begin{array}{c}\text { NAD-dependent protein lipoamidase sirtuin-4, } \\
\text { mitochondrial (EC 2.3.1.-) (NAD-dependent } \\
\text { ADP-ribosyltransferase sirtuin-4) (EC 2.4.2.-) } \\
\text { (NAD-dependent protein deacetylase sirtuin-4) } \\
\text { (EC 2.3.1.286) (regulatory protein SIR2 homolog 4) } \\
\text { (SIR2-like protein 4) }\end{array}$ & 35,188 & & \\
\hline Q8N6S4 & Ankyrin repeat domain-containing protein $13 \mathrm{C}$ & 60,818 & & \\
\hline Q9UHR4 & $\begin{array}{l}\text { Brain-specific angiogenesis inhibitor } 1 \text {-associated protein } \\
\text { 2-like protein } 1 \text { (BAI1-associated protein } 2 \text {-like protein } \\
\text { 1) (insulin receptor tyrosine kinase substrate) }\end{array}$ & 56,883 & & \\
\hline B2RUY7 & $\begin{array}{l}\text { von Willebrand factor C domain-containing protein } \\
\text { 2-like (Brorin-like) }\end{array}$ & 24,570 & & \\
\hline Q9Y3F4 & $\begin{array}{c}\text { Serine-threonine kinase receptor-associated protein } \\
\text { (MAP activator with WD repeats) (UNR-interacting } \\
\text { protein) (WD-40 repeat protein PT-WD) }\end{array}$ & 38,438 & & \\
\hline Q8TCV5 & $\begin{array}{l}\text { WAP four-disulfide core domain protein } 5 \text { (putative } \\
\text { protease inhibitor WAP1) (p53-responsive gene } 5 \\
\text { protein) }\end{array}$ & 24,238 & & \\
\hline O60568 & $\begin{array}{l}\text { Multifunctional procollagen lysine hydroxylase and } \\
\text { glycosyltransferase LH3 (including procollagen-lysine, } \\
\text { 2-oxoglutarate 5-dioxygenase } 3 \text { (EC 1.14.11.4) (lysyl } \\
\text { hydroxylase 3) (LH3); procollagen glycosyltransferase } \\
\text { (EC 2.4.1.50) (EC 2.4.1.66) (galactosylhydroxylysine- } \\
\text { glucosyltransferase) (procollagen galactosyltransferase) }\end{array}$ & 84,785 & $\begin{array}{l}\text { N-linked } \\
\text { (GlcNAc) } \\
\text { asparagine }\end{array}$ & \\
\hline Q7Z7J5 & $\begin{array}{l}\text { Developmental pluripotency-associated protein } 2 \\
\text { (pluripotent embryonic stem cell-related gene } 1 \text { protein) }\end{array}$ & 33,784 & & \\
\hline Q8N6C5 & $\begin{array}{l}\text { Immunoglobulin superfamily member } 1 \text { (IgSF1) } \\
\text { (immunoglobulin-like domain-containing protein } 1) \\
\text { (inhibin-binding protein) (InhBP) (pituitary } \\
\text { gland-specific factor } 2)(\mathrm{p} 120)\end{array}$ & 148,936 & $\begin{array}{l}\text { N-linked } \\
\text { (GlcNAc) } \\
\text { asparagine }\end{array}$ & \\
\hline Q04837 & $\begin{array}{l}\text { Single-stranded DNA-binding protein, mitochondrial } \\
\text { (Mt-SSB) (MtSSB) (PWP1-interacting protein 17) }\end{array}$ & 17,260 & & \\
\hline Q7RTX1 & $\begin{array}{r}\text { Taste receptor type } 1 \text { member } 1 \text { (G protein-coupled } \\
\text { receptor } 70)\end{array}$ & 93,074 & $\begin{array}{l}\text { N-linked } \\
\text { (GlcNAc) } \\
\text { asparagine }\end{array}$ & \\
\hline P13994 & $\begin{array}{l}\text { Coiled-coil domain-containing protein } 130(9 \mathrm{kDa} \\
\text { protein })\end{array}$ & 44,802 & & \\
\hline Q5T440 & $\begin{array}{l}\text { Putative transferase CAF17, mitochondrial (EC 2.1.-.-) } \\
\quad \text { (iron-sulfur cluster assembly factor homolog) }\end{array}$ & 38,155 & & \\
\hline A7E2S9 & $\begin{array}{l}\text { Putative ankyrin repeat domain-containing protein } \\
\text { 30B-like }\end{array}$ & 28,549 & & \\
\hline Q6QNK2 & $\begin{array}{l}\text { Adhesion } G \text { protein-coupled receptor D1 } \\
\text { (G protein-coupled receptor 133) } \\
\text { (G protein-coupled receptor PGR25) }\end{array}$ & 96,530 & $\begin{array}{l}\text { N-linked } \\
\text { (GlcNAc) } \\
\text { asparagine }\end{array}$ & \\
\hline Q8NBR0 & $\begin{array}{l}\text { Tumor protein p53-inducible protein } 13 \\
\text { (damage-stimulated cytoplasmic protein } 1 \text { ) }\end{array}$ & 42,238 & & \\
\hline
\end{tabular}


TABle 4: Continued.

\begin{tabular}{|c|c|c|c|c|}
\hline $\begin{array}{l}\text { Protein } \\
\text { ID }\end{array}$ & Protein names & Mass & Glycosylation & Posttranslational modification \\
\hline A2VDJ0 & Transmembrane protein 131-like & 179,339 & $\begin{array}{l}\text { N-linked } \\
\text { (GlcNAc) } \\
\text { asparagine }\end{array}$ & \\
\hline Q9NZT2 & $\begin{array}{l}\text { Opioid growth factor receptor (OGFr) } \\
\text { (protein 7-60) (zeta-type opioid receptor) }\end{array}$ & 73,325 & & \\
\hline P62910 & $\begin{array}{l}\text { 60S ribosomal protein L32 (large ribosomal } \\
\text { subunit protein eL32) }\end{array}$ & 15,860 & & \\
\hline Q8WXI2 & $\begin{array}{c}\text { Connector enhancer of kinase suppressor of ras } 2 \\
\text { (connector enhancer of KSR 2) (CNK homolog } \\
\text { protein 2) (CNK2) }\end{array}$ & 117,535 & & PTM: phosphorylated on tyrosine \\
\hline O95396 & $\begin{array}{l}\text { Adenylyltransferase and sulfurtransferase MOCS3 } \\
\text { (molybdenum cofactor synthesis protein 3) } \\
\text { (molybdopterin synthase sulfurylase) (MPT synthase } \\
\text { sulfurylase) (including molybdopterin-synthase } \\
\text { adenylyltransferase (EC 2.7.7.80) (adenylyltransferase } \\
\text { MOCS3) (sulfur carrier protein MOCS2A } \\
\text { adenylyltransferase); molybdopterin-synthase } \\
\text { sulfurtransferase (EC 2.8.1.11) (sulfur carrier protein } \\
\text { MOCS2A sulfurtransferase) (sulfurtransferase MOCS3)) }\end{array}$ & 49,669 & & \\
\hline Q8IVN8 & $\begin{array}{l}\text { Somatomedin-B and thrombospondin type-1 } \\
\text { domain-containing protein (RPE-spondin) }\end{array}$ & 29,610 & $\begin{array}{l}\text { N-linked } \\
\text { (GlcNAc) } \\
\text { asparagine }\end{array}$ & \\
\hline P55055 & $\begin{array}{c}\text { Oxysterol receptor LXR-beta (liver X receptor beta) } \\
\text { (nuclear receptor NER) (nuclear receptor subfamily } \\
1 \text { group H member 2) (ubiquitously expressed } \\
\text { nuclear receptor) }\end{array}$ & 50,974 & & $\begin{array}{l}\text { PTM: sumoylated by SUMO2 at Lys- } \\
409 \text { and Lys- } 447 \text { during the hepatic } \\
\text { acute phase response }\end{array}$ \\
\hline Q7Z3I7 & Zinc finger protein 572 & 61,238 & & \\
\hline Q9Y580 & RNA-binding protein 7 (RNA-binding motif protein 7) & 30,504 & & $\begin{array}{l}\text { PTM: phosphorylated at Ser-136 by } \\
\text { MAPK14/p38-alpha-activated } \\
\text { MAPKAPK2/MK2 }\end{array}$ \\
\hline P48729 & $\begin{array}{c}\text { Casein kinase I isoform alpha (CKI-alpha) (EC 2.7.11.1) } \\
(\mathrm{CK} 1)\end{array}$ & 38,915 & & \\
\hline P19532 & $\begin{array}{l}\text { Transcription factor E3 (class E basic helix-loop-helix } \\
\text { protein 33) (bHLHe33) }\end{array}$ & 61,521 & & $\begin{array}{l}\text { PTM: phosphorylation by MTOR } \\
\text { regulates its subcellular location and } \\
\text { activity }\end{array}$ \\
\hline Q8WXH4 & Ankyrin repeat and SOCS box protein 11 (ASB-11) & 35,367 & & \\
\hline Q86U42 & $\begin{array}{l}\text { Polyadenylate-binding protein } 2(\mathrm{PABP}-2) \\
\text { (poly }(\mathrm{A}) \text {-binding protein } 2) \text { (nuclear poly }(\mathrm{A}) \text {-binding } \\
\text { protein } 1)(\text { poly }(\mathrm{A})-\text {-binding protein } \mathrm{II})(\mathrm{PABII}) \\
\text { (polyadenylate-binding nuclear protein } 1)\end{array}$ & 32,749 & & $\begin{array}{l}\text { PTM: arginine dimethylation is } \\
\text { asymmetric and involves PRMT1 and } \\
\text { PRMT3 }\end{array}$ \\
\hline Q96MT1 & RING finger protein 145 (EC 2.3.2.27) & 75,617 & & \\
\hline P17643 & $\begin{array}{c}\text { 5,6-Dihydroxyindole-2-carboxylic acid oxidase (DHICA } \\
\text { oxidase) (EC 1.14.18.-) (catalase B) (glycoprotein 75) } \\
\text { (melanoma antigen gp75) (tyrosinase-related protein 1) } \\
\text { (TRP) (TRP-1) (TRP1) }\end{array}$ & 60,724 & $\begin{array}{l}\text { N-linked } \\
\text { (GlcNAc) } \\
\text { asparagine }\end{array}$ & PTM: glycosylated \\
\hline Q9NW75 & G patch domain-containing protein 2 & 58,944 & & \\
\hline Q09472 & $\begin{array}{l}\text { Histone acetyltransferase p300 (p300 HAT) (EC 2.3.1.48) } \\
\text { (E1A-associated protein p300) (histone } \\
\text { butyryltransferase p300) (EC 2.3.1.-) (histone } \\
\text { crotonyltransferase p300) (EC 2.3.1.-) (protein } \\
\text { 2-hydroxyisobutyryltransferase p300) (EC 2.3.1.-) } \\
\text { (protein lactyltransferase p300) (EC 2.3.1.-) } \\
\text { (protein propionyltransferase p300) (EC 2.3.1.-) }\end{array}$ & 264,161 & & $\begin{array}{c}\text { PTM: acetylated on Lys at up to } 17 \\
\text { positions by intermolecular } \\
\text { autocatalysis }\end{array}$ \\
\hline
\end{tabular}


TABLE 4: Continued.

\begin{tabular}{|c|c|c|c|c|}
\hline $\begin{array}{l}\text { Protein } \\
\text { ID }\end{array}$ & Protein names & Mass & Glycosylation & Posttranslational modification \\
\hline P58173 & $\begin{array}{l}\text { Olfactory receptor 2B6 (Hs6M1-32) (olfactory receptor } \\
\text { 2B1) (olfactory receptor 2B5) (olfactory receptor 5-40) } \\
\text { (OR5-40) (olfactory receptor 6-31) (OR6-31) } \\
\text { (olfactory receptor OR6-4) }\end{array}$ & 35,414 & $\begin{array}{l}\text { N-linked } \\
\text { (GlcNAc) } \\
\text { asparagine }\end{array}$ & \\
\hline Q15776 & $\begin{array}{c}\text { Zinc finger protein with KRAB and SCAN domains } 8 \\
\text { (LD5-1) (zinc finger protein 192) }\end{array}$ & 65,816 & & \\
\hline
\end{tabular}

TABle 5: Glycoprotein classification in AD patients: upregulated and downregulated.

\begin{tabular}{lc}
\hline Classification & Percentage \\
\hline Upregulated glycoproteins & \\
Protein-binding activity modulator (PC00095) & $16.70 \%$ \\
Gene-specific transcriptional regulator (PC00264) & $12.50 \%$ \\
Metabolite interconversion enzyme (PC00262) & $12.50 \%$ \\
Protein-modifying enzyme (PC00260) & $8.30 \%$ \\
Transporter (PC00227) & $8.30 \%$ \\
Nucleic acid metabolism protein (PC00171) & $8.30 \%$ \\
Transmembrane signal receptor (PC00197) & $8.30 \%$ \\
Scaffold/adaptor protein (PC00226) & $4.20 \%$ \\
Defense/immunity protein (PC00090) & $4.20 \%$ \\
Cytoskeletal protein (PC00085) & $4.20 \%$ \\
Structural protein (PC00211) & $4.20 \%$ \\
Extracellular matrix protein (PC00102) & $4.20 \%$ \\
Translational protein (PC00263) & $4.20 \%$ \\
Downregulated glycoproteins & \\
Metabolite interconversion enzyme (PC00262) & $13.70 \%$ \\
Nucleic acid metabolism protein (PC00171) & $12.40 \%$ \\
Protein-modifying enzyme (PC00260) & $12.40 \%$ \\
Gene-specific transcriptional regulator (PC00264) & $9.90 \%$ \\
Transmembrane signal receptor (PC00197) & $9.30 \%$ \\
Scaffold/adaptor protein (PC00226) & $6.80 \%$ \\
Transporter (PC00227) & $6.20 \%$ \\
Protein-binding activity modulator (PC00095) & $5.00 \%$ \\
Translational protein (PC00263) & $5.00 \%$ \\
Defense/immunity protein (PC00090) & $3.50 \%$ \\
Intercellular signal molecule (PC00207) & $3.70 \%$ \\
Cytoskeletal protein (PC00085) & $3.10 \%$ \\
Chromatin/chromatin-binding or & $2.50 \%$ \\
chromatin-regulatory protein (PC00077) & $0.60 \%$ \\
Membrane traffic protein (PC00150) & \\
Cell adhesion molecule (PC00069) & \\
Structural protein (PC00211) & \\
Extracellular matrix protein (PC00102) & \\
\hline
\end{tabular}

signaling [28-31]. Ubiquitin-fold modifier-conjugating enzyme 1 (UFC1) was upregulated in our AD cohort. This enzyme is a component of UFM1 (ubiquitin-fold modifier 1), which is responsible for UFMylation and required for E1 activating enzymes, E2 conjugating enzymes, and an E3 ligase [32]. UFMylation is tightly related to endoplasmic reticulum (ER) stress and is involved in protein folding and secretion. The consequences of ER stress may lead to the amyloid cascade, tau phosphorylation, and synaptic dysfunction [33]. Kinesinlike protein KIF28P (KIF28P), a kinesin-3 vesicle transport protein [34], was also upregulated in the $\mathrm{AD}$ group. Data related to KIF28P and $\mathrm{AD}$ are limited; however, evidence indicates that KIF1A, belonging to the kinesin-3 family, is a neuron-specific kinesin [34]. It has a primary role in the anterograde transport of beta-secretase (BACE1), as determined by abnormal accumulation of BACE1 at presynaptic terminals in the postmortem AD brain [35]. The elevation of local BACE1 levels can promote the generation of $\mathrm{A} \beta$, contributing to the development of AD [36]. Ras-related protein Rab-6A (RAB6A) is a low molecular weight GTPase that belongs to the Ras superfamily and regulates retrograde Golgi-ER trafficking, transport of early endosomes and recycling endosomes to the trans-Golgi network, and vesicle exocytosis [37]. Previous studies reported significant associations of RAB6A with AD pathology, including increased levels in AD brains [38], which affects APP trafficking and $A \beta$ generation [39] and modulates the AD-related unfolded protein response [38]. Coagulation factor X (FX), a vitamin K-dependent glycoprotein, was also upregulated in $\mathrm{AD}$ sera. FX plays a central role in the activation of prothrombin to thrombin in the presence of calcium ions in the blood coagulation cascade [40]. Thrombin is a key mediator of coagulation and inflammation via proteolytic and receptor-mediated mechanisms. Thrombin acts as a vascular-derived inflammatory protein that can activate both microglia and astrocytes, resulting in release of inflammatory proteins, reactive oxygen species, and proteases [41]. Induction of proinflammatory cytokines, including IL- $1 \beta$, IL- 6 , and TNF- $\alpha$, by thrombin is also evidence for cerebral vasculature damage contributing to neuroinflammation and neuronal injury in $\mathrm{AD}$ [42].

Among the downregulated glycoproteins found in our study, C-type mannose receptor 2 (MRC2) is from the family of endocytic receptors. MRC2 is involved in the intracellular collagen degradation pathway in biological and pathological processes [43]. The endocytic pathway (EP) has been described to have early endosomal abnormalities in subtypes of $\mathrm{AD}$, resulting in amyloid beta generation and APOE dysfunction [44]. MRC2 is also downregulated in aging human microglia [45]. Another downregulated protein found in this study is FAS-associated factor 2 (FAF2). FAF2 has an important role in endoplasmic reticulum- 
TABLE 6: Unique glycoproteins in the AD group classified by the molecular function, biological process, and pathways.

\begin{tabular}{|c|c|c|c|}
\hline Classification & $\begin{array}{l}\text { Percentage } \\
(\%)\end{array}$ & Classification & $\begin{array}{l}\text { Percentage } \\
(\%)\end{array}$ \\
\hline Molecular function & & Pathways & \\
\hline $\begin{array}{l}\text { Organic cyclic compound binding } \\
\text { (GO:0097159) }\end{array}$ & 26.0 & Alzheimer disease-presenilin pathway (P00004) & $16.60 \%$ \\
\hline $\begin{array}{l}\text { Heterocyclic compound binding } \\
\text { (GO:1901363) }\end{array}$ & 26.0 & $\begin{array}{l}\text { Inflammation mediated by chemokine and cytokine signaling } \\
\text { pathway (P00031) }\end{array}$ & $9.20 \%$ \\
\hline Protein binding (GO:0005515) & 24.7 & Apoptosis signaling pathway (P00006) & $5.10 \%$ \\
\hline Ion binding (GO:0043167) & 5.5 & Integrin signaling pathway (P00034) & $5.10 \%$ \\
\hline Small molecule binding (GO:0036094) & 5.5 & Wnt signaling pathway (P00057) & $5.10 \%$ \\
\hline Carbohydrate binding (GO:0030246) & 5.6 & p53 pathway (P00059) & $3.70 \%$ \\
\hline $\begin{array}{l}\text { Carbohydrate derivative binding } \\
\text { (GO:0097367) }\end{array}$ & 4.1 & Metabotropic glutamate receptor group III pathway (P00039) & $2.60 \%$ \\
\hline $\begin{array}{l}\text { Protein-containing complex binding } \\
\text { (GO:0044877) }\end{array}$ & 2.7 & Ionotropic glutamate receptor pathway (P00037) & $2.60 \%$ \\
\hline Biological process & & Gamma-aminobutyric acid synthesis (P04384) & $2.60 \%$ \\
\hline Cellular process (GO:0009987) & $32.30 \%$ & Dopamine receptor-mediated signaling pathway (P05912) & $2.60 \%$ \\
\hline Metabolic process (GO:0008152) & $15.50 \%$ & p53 pathway feedback loops 2 (P04398) & $2.60 \%$ \\
\hline Biological regulation (GO:0065007) & $15.10 \%$ & Endothelin signaling pathway (P00019) & $2.60 \%$ \\
\hline Response to stimulus (GO:0050896) & $9.20 \%$ & Parkinson disease (P00049) & $2.60 \%$ \\
\hline Localization (GO:0051179) & $8.00 \%$ & EGF receptor signaling pathway (P00018) & $2.60 \%$ \\
\hline Signaling (GO:0023052) & $6.40 \%$ & PDGF signaling pathway (P00047) & $2.60 \%$ \\
\hline Developmental process (GO:0032502) & $4.80 \%$ & Ras pathway (P04393) & $2.60 \%$ \\
\hline $\begin{array}{l}\text { Multicellular organismal process } \\
\text { (GO:0032501) }\end{array}$ & $4.80 \%$ & Notch signaling pathway (P00045) & $2.60 \%$ \\
\hline \multirow[t]{3}{*}{ Others } & $4.0 \%$ & $\begin{array}{l}\text { Muscarinic acetylcholine receptor } 2 \text { and } 4 \text { signaling pathway } \\
\text { (P00043) }\end{array}$ & $2.60 \%$ \\
\hline & & Cadherin signaling pathway (P00012) & $2.60 \%$ \\
\hline & & Metabotropic glutamate receptor group I pathway (P00041) & $2.60 \%$ \\
\hline \multirow[t]{10}{*}{$\begin{array}{l}\text { Carbohydrate derivative binding } \\
\text { (GO:0097367) }\end{array}$} & 4.1 & Metabotropic glutamate receptor group II pathway (P00040) & $2.60 \%$ \\
\hline & & CCKR signaling map (P06959) & $2.60 \%$ \\
\hline & & Beta2 adrenergic receptor signaling pathway (P04378) & $2.60 \%$ \\
\hline & & Formyltetrahydroformate biosynthesis (P02743) & $2.60 \%$ \\
\hline & & Beta1 adrenergic receptor signaling pathway (P04377) & $2.60 \%$ \\
\hline & & 5HT1 type receptor-mediated signaling pathway (P04373) & $2.60 \%$ \\
\hline & & Transcription regulation by bZIP transcription factor (P00055) & $2.60 \%$ \\
\hline & & GABA-B receptor II signaling (P05731) & $2.60 \%$ \\
\hline & & Enkephalin release (P05913) & $1.50 \%$ \\
\hline & & B cell activation (P00010) & $1.00 \%$ \\
\hline
\end{tabular}

associated degradation, which mediates ubiquitin-dependent degradation of misfolded ER proteins [46]. Significant underexpression of FAF2 was determined in the frontal cortex of AD patients [47]. SIRT4 was downregulated in AD patients. The potential role of sirtuins in AD and other neurodegenerative disorders has been described. Reductions of SIRT1 and SIRT3 mRNA/protein levels were observed in $\mathrm{AD}$ brains correlating with the stage/duration of the disease [48]. In addition, increased expression of SIRT4 after shortterm treatment with extracellular $\mathrm{A} \beta 1-42$ oligomers indicates a more complex association between APP/A $\beta$ and SIRTs [49]. Ankyrin repeat domain-containing protein 13C
(ANKRD13C) was also downregulated in AD. This glycoprotein acts as a molecular chaperone for $G$ proteincoupled receptors (GPCRs), regulating their biogenesis and exit from the ER [50]. Alterations of GPCRs can lead to interaction between GPCRs and $\beta$-site APP cleaving enzyme 1 (BACE1), a key secretase in AD pathogenesis [51]. Brainspecific angiogenesis inhibitor 1-associated protein 2-like protein 1 (BAIAP2L1), also known as insulin receptor tyrosine kinase substrate (IRTKS), is a novel regulator of the insulin network [52]. IRTKS-deficient mice exhibit insulin resistance, including hyperglycemia, hyperinsulinemia, glucose intolerance, decreased insulin sensitivity, and increased 


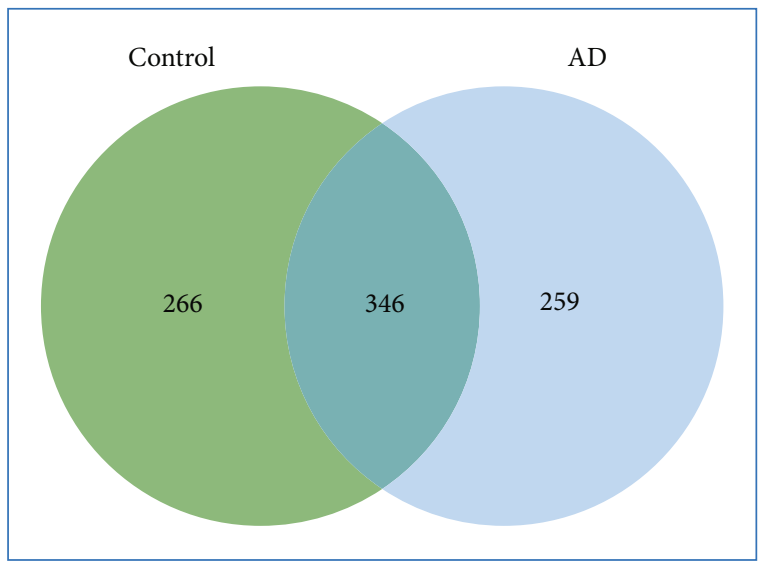

Figure 1: Venn diagrams displaying the number of identified unique glycoproteins for control and $\mathrm{AD}$ groups.

hepatic glucose production [53]. Insulin dysregulation can contribute to $\mathrm{AD}$ through a role in proteostasis. Insulin resistance can lead to abnormal clearance of amyloid $\beta$ peptide and phosphorylation of tau, along with effects on vasoreactivity, lipid metabolism, and inflammation [54].

Further analysis of 259 unique glycoproteins in the AD group categorized the main proteins as binding activity (41.7\%) for molecular function, cellular process $(27.5 \%)$ for biological process, and Alzheimer's disease-presenilin pathway (16.6\%) for pathway. Previous studies have shown main plasma proteins classified as acute-phase response (upregulated) and platelet degranulation (downregulated) for biological process. It also classified them as complementcomponent $\mathrm{Clq}$ binding (upregulated) and serine-type endopeptidase inhibitor activity (downregulated) for molecular function [55]. To get a general overview of serum glycoprotein interactions in $\mathrm{AD}$ and to search for the most affected pathways involving the candidate proteins, analysis with the STITCH database was performed (Figure 2). Three KEGG pathways were highlighted: apoptosis, AD pathway, and TNF signaling pathway. For apoptosis pathways, protein networks with MAPT, APOE, APP, PSEN1, and PSEN2 included a disintegrin and metalloproteinase (ADAM10), LDL receptor-related protein (LRP1), polyamine-transporting ATPase 13A2 (ATP13A2), proneuregulin-2, membranebound isoform (NRG2), Desmoplakin (DSP), Rho guanine nucleotide exchange factor 12 (ARHGEF12), citron Rhointeracting kinase (CIT), and protein phosphatase 1 regulatory subunit 9A (PPP1R9A). ADAM10 is the main $\alpha$-secretase that cleaves APP in the nonamyloidogenic pathway, and it plays a critical role in reducing the generation of $\mathrm{A} \beta$ peptides [56]. LRP1 regulates $\mathrm{A} \beta$ metabolism in the brain and brain homeostasis. The impairment of these processes results in $\mathrm{AD}$ pathology [57]. ATP13A2 is a late endolysosomal transporter. Loss of function of this protein results in lysosomal deficiency as a consequence of impaired lysosomal export of the polyamines spermine/spermidine, and it is implicated in neurodegenerative disorders [58]. Another glycoprotein, NRG2, is a neuregulin (NRG), a family of epidermal growth factor- (EGF-) related proteins. Dysregulation of this glycoprotein can lead to abnormal synaptic plasticity in the hippocampus and $\mathrm{AD}$ develop- ment [59]. DSP is a component of the adherence junction complex and plays a role in endothelial cell (EC) shear stress and/or hypoxia regulation. Higher expression of DSP in intracranial ECs suggests stronger cell-cell contact between intracranial ECs compared with extracranial ECs, which affects the blood-brain barrier of the cerebral microvasculature [60]. Proteome-based assessment of plasma biomarkers in 511 subjects with $\mathrm{AD}$ along with other neurodegenerative diseases and normal older people showed that DSP was upregulated in the $\mathrm{AD}$ group [61]. ARHGEF12 plays a role in the regulation of RhoA GTPase and in the RhoA/RhoA kinase pathway [62]. Impairment of these Rho GTPases contributes to the increase in $\mathrm{A} \beta$ resulting in neurotoxicity, as seen in $\mathrm{AD}$ [63]. CIT is a tissue-specific Ser/Thr kinase that targets the Rho-Racbinding protein, citron. In AD brains, dysregulation of RhoRac1-GTPase signaling contributes to synaptic degeneration, amyloid precursor protein (APP) processing, and an increase in tau phosphorylation [64]. PPP1R9A or Neurabin-1 plays an important role in synaptic structure and function and neurite formation. In addition, abnormal protein phosphatase activity can cause hyperphosphorylation and lead to the aberrant accumulation of $\mathrm{A} \beta$ plaques. It can also lead to the intracellular formation of hyperphosphorylated tau protein together with synaptopathology in $\mathrm{AD}$ [65].

Interaction of proteins potentially related to apoptosis pathways were found in the $\mathrm{AD}$ group, including caspase 10 (CASP10) and FAS-associated death domain protein (FADD) (Figure 2). CASP10 is an apical caspase. When a death signal triggers an apoptotic pathway, apical caspases are activated that then activate effector caspases by proteolytic cleavage, which leads to apoptotic cell death [66]. Human CASP10 is highly homologous to caspase- 8 and the role of CASP10 is also FADD-dependent; however, its role in the extrinsic apoptotic cascade is still not clear [66]. A previous study of AD cases revealed that caspase- 8 and its downstream effector, caspase-3, are involved in synaptic plasticity, learning and memory, and control of microglia proinflammatory activation and associated neurotoxicity, which is indicated in AD pathology [67]. FADD is an adaptor protein involved in initiating apoptosis and in extrinsic/ death receptor-mediated apoptosis. However, along with serine/threonine kinases, it is also responsible for the initiation of necroptosis [68]. A study of the possible contribution of apoptotic processes and other pathological cascades in the degeneration of cholinergic neurons in $\mathrm{AD}$ indicated that FADD apoptotic signaling may be triggered within basal forebrain cholinergic neurons in AD [69]. KEGG pathway analysis in this study indicated the TNF signaling pathway to be involved in protein-protein interaction. Tumor necrosis factor receptor superfamily member $1 \mathrm{~B}$ (TNFRSF1B), also known as TNFR2, was the main glycoprotein reported in AD patients. Transgenic mice expressing human TNFR2 in primary oligodendrocytes showed that specific activation of TNFR2 rescues neurons and oligodendrocytes from oxidative stress and promotes oligodendrocyte differentiation and myelination [70]. Another gene-targeting study to delete TNFR2 in an AD transgenic mouse model found overexpression of TNFR2 ameliorated progression of the disease. These findings reinforce a neuroprotective function of 


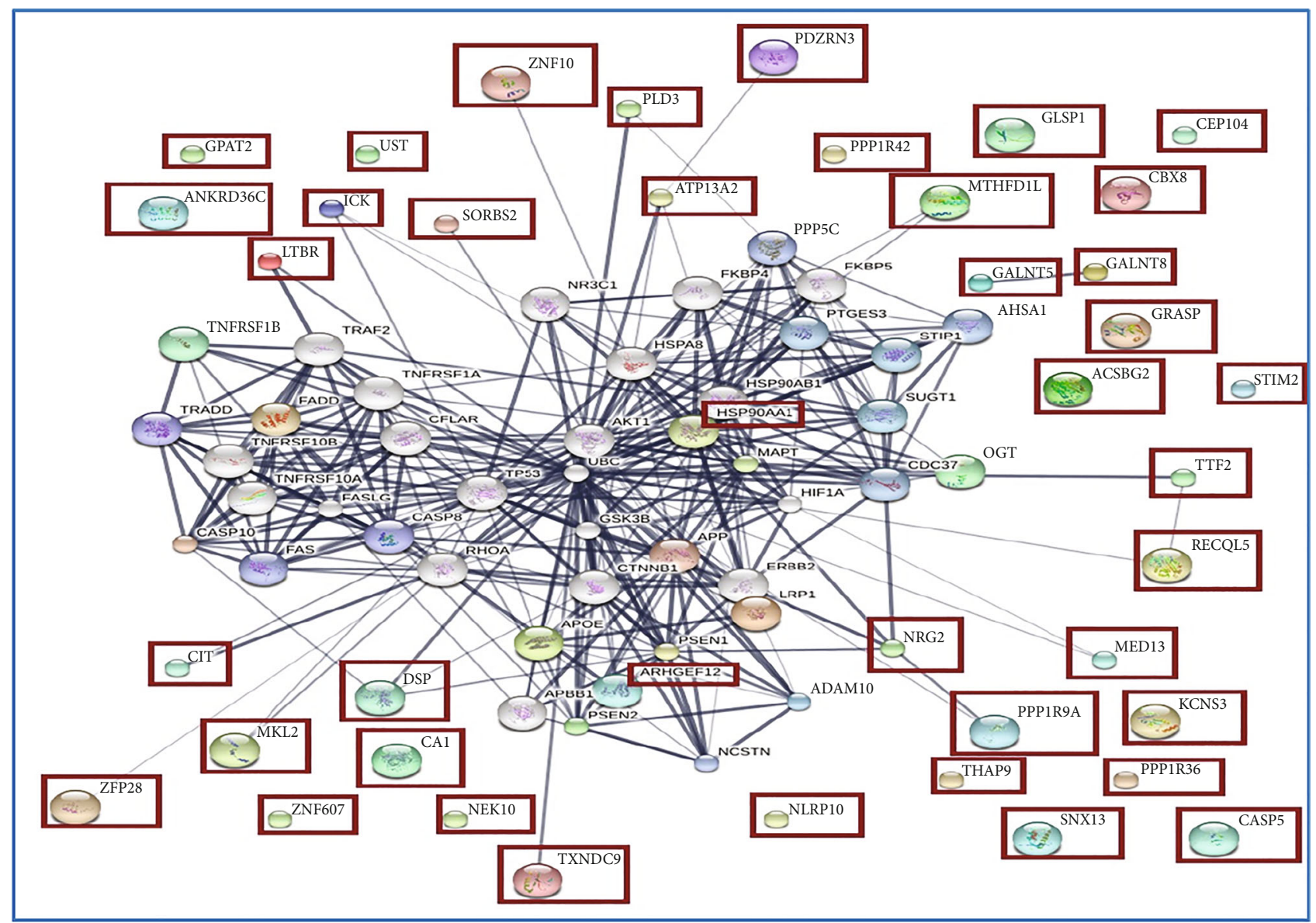

FIGURE 2: Protein-protein interaction identified from serum of the AD group. Stronger associations are represented by thicker lines. Proteinprotein interactions are shown in grey, chemical-protein interactions in green, and interactions between chemicals in red.

TNFR2 in AD pathology [71]. We identified other glycoprotein interactions potentially related to $\mathrm{AD}$ pathology. The $\mathrm{E} 3$ ubiquitin-protein ligase, PDZRN3, promotes endocytosis and lysosomal degradation and is involved in the protein ubiquitination pathway [72]. Crosstalk between the enzymes that regulate protein ubiquitination and the toxic proteins, Tau and $\mathrm{A} \beta$, were highlighted for next-generation therapeutics strategies [73]. The $5^{\prime}-3^{\prime}$ exonuclease PLD3 (PLD3), also found in the protein interaction analysis, regulates inflammatory cytokine responses via degradation of nucleic acids by reducing the concentration of single strand DNA able to stimulate Toll-Like Receptor 9 (TLR9) [74]. Stimulation of innate immunity via TLR9 in a transgenic mouse model of $\mathrm{AD}$ was highly effective at reducing the parenchymal and vascular amyloid burden, along with $\mathrm{A} \beta$ oligomers [75]. Thioredoxin domaincontaining protein 9 (TXNDC9) or phosducin-like protein 3 (PHLP3) has ATP binding activity. TXNDC9 regulates the ATPase activity of chaperonin T-complex protein 1 complex, a key complex for protein folding, and it diminishes actin and tubulin folding [76]. Misfolded tubulin aggregates, accumulates, and tangles in plaques, a hallmark of $\mathrm{AD}$. Mass spectrometry analysis identified significant decreases of human brain $\mathrm{t}$-complex polypeptide 1 and $\beta 1$ tubulin in the temporal, frontal and parietal cortex and thalamus of patients with $\mathrm{AD}$ [77].
In this study, we have identified many proteins associated with $\mathrm{AD}$; however, there are several important limitations. The first is differences in age and education between control and AD groups. Higher age and lower education were reported as having a greater risk for dementia, but the outcomes are not always consistent [78]. Nevertheless, obtaining a larger number of cases and healthy controls for stratified age groups, educational level, and APOE haplotypes will be beneficial for clarifying differences in protein profiles. This is an essential step for both effective and achievable clinical application. Another limitation involves the blood-brain barrier that may contribute to some obstacles of interpretation between proteins in the blood and their association in brain. The last limitation is that we did not measure relevant neurodegenerative biomarkers such as tau, $\mathrm{A} \beta 40$, and 42 proteins in $\mathrm{AD}$ cases. Future work is necessary to evaluate these hallmarks and their impact on the protein profiles.

\section{Conclusions}

Our mass spectrometry-based proteomic study of $\mathrm{AD}$ patients and normally cognitive controls is an efficient and comprehensive way to identify thousands of proteins in 
serum samples. These protein changes can clarify some gaps in our understanding about the molecular mechanisms that underlie the pathogenesis of AD. Network glycoproteome analysis not only reveals a highly reproducible and integrated window into the complex biochemical and cellular alterations in the serum of individuals with $\mathrm{AD}$ but also fulfills many clinical needs in $\mathrm{AD}$ diagnostics, disease monitoring, and therapeutics.

\section{Abbreviations}

$\mathrm{A} \beta$ :

$\mathrm{AD}$ :

ADAM10:

ADAMTS8:

AGEs:

ANKRD13C:

APOE:

APP:

ARHGEF12:

ATP13A2:

BAIAP2L1:

CASP10:

CIT:

EC:

ECLIA:

EOAD:

DSP:

FADD:

FAF2:

FBG:

FX:

GlcNAC:

GPCRs:

GSK3 $\beta$ :

HbAlc:

HDL-cholesterol:

MAPT:

MCP-1:

MRC2:

NRG2:

IL:

IRTKS:

LC/LC-MS/MS:

LDL-cholesterol:

LOAD:

LRP1:

KEGG:

KIF28P:

PCR:

PLD3:
Amyloid beta

Alzheimer's disease

A disintegrin and metalloproteinase

A disintegrin and metalloproteinase with thrombospondin motifs 8

Advanced glycation end products

Ankyrin repeat domain-containing protein $13 \mathrm{C}$

Apolipoprotein E

Amyloid-beta precursor protein

Rho guanine nucleotide exchange factor 12

Polyamine-transporting ATPase 13A2

Brain-specific angiogenesis inhibitor 1associated protein 2 -like protein 1

Caspase 10

Citron Rho-interacting kinase

Endothelial cell

Electrochemiluminescence

immunoassays

Early-onset AD

Desmoplakin

FAS-associated death domain protein

FAS-associated factor 2

Fasting blood glucose

Coagulation factor $\mathrm{X}$

$\mathrm{N}$-Acetyl glucosamine

$\mathrm{G}$ protein-coupled receptors

Glycogen synthase kinase $3 \beta$

Glycated hemoglobin

High-density lipoprotein cholesterol

Microtubule-associated protein tau

Macrophage chemotactic protein-1

C-type mannose receptor 2

Proneuregulin-2, membrane-bound isoform

Interleukin

Insulin receptor tyrosine kinase substrate

Liquid chromatography and tandem

mass spectrometry

Low-density lipoprotein cholesterol

Late-onset AD

LDL receptor-related protein

Kyoto Encyclopedia of Genes and

Genomes

Kinesin-like protein KIF28P

Polymerase chain reaction

Phospholipase D3
PDZRN3:

PDZ domain-containing RING finger

protein 3

PHLP3: $\quad$ Phosducin-like protein 3

PI3K: Phosphatidylinositol-3-kinase

PKB/Akt: $\quad$ Protein kinase B

PPP1R9A: $\quad$ Protein phosphatase 1 regulatory subunit 9A

PSEN1: $\quad$ Presenilin 1

PSEN2: $\quad$ Presenilin 2

RAB6A: Ras-related protein Rab-6A

RAGEs: $\quad$ Receptor of advanced glycation end products

SIRT4: NAD-dependent protein lipoamidase sirtuin-4, mitochondrial

TG:

TNF:

TXNDC9:

Wnt:

Triglyceride

Tumor necrosis factor

Thioredoxin domain-containing protein

9

Wingless-type MMTV integration site

family member

UFC1: $\quad$ Ubiquitin-fold modifier-conjugating enzyme 1.

\section{Data Availability}

The data supporting these findings are available from the corresponding author upon reasonable request.

\section{Conflicts of Interest}

The authors report no conflicts of interest associated with this work.

\section{Authors' Contributions}

NK and JS conceived and designed the study. NK, JS, and SR discussed the data and revised the main manuscript. All authors made substantial contributions to the acquisition and interpretation of data, drafted the article, and critically revised it for important intellectual content. All authors gave the final approval of the version to be published and agreed to be accountable for all aspects of the work.

\section{Acknowledgments}

We would like to thank all AD patients from the geriatric and psychiatry (memory) outpatient clinics (Faculty of Medicine Ramathibodi Hospital, Mahidol University), participants from the EGAT Study, and the health team of the Faculty of Medicine Ramathibodi Hospital, Mahidol University. For proteomic analysis, we thank Mr. Yodying Yingchutrakul and Mr. Sucheewin Krobthong who gave us ac6cess to the proteomic research laboratory, National Center for Genetic Engineering and Biotechnology (BIOTEC), and research facilities. This work was funded by the Development Potentials of Thai People Project, Faculty of Medicine Ramathibodi Hospital, Mahidol University, and the project of Higher Education Research Promotion and National Research University Development, Office of the Higher Education Commission. 


\section{Supplementary Materials}

Data in this part is presented in Supplementary Table 1 that identifies all downregulated glycoproteins from serum of the AD group. (Supplementary Materials)

\section{References}

[1] Alzheimer's Association Report, "2021 Alzheimer's disease facts and figures," Alzheimer's \& Dementia, vol. 17, no. 3, pp. 327-406, 2021.

[2] W. He, D. Goodkind, P. Kowal, and US Census Bureau, International Population Reports, P95/16-1, An Aging World: 2015, U.S. Government Publishing Office, Washington, D.C., 2016, http://www.census.gov/content/dam/Census/library/ publications/2016/demo/p95-16-1.pdf.

[3] K. B. Rajan, J. Weuve, L. L. Barnes, E. A. McAninch, R. S. Wilson, and D. A. Evans, "Population estimate of people with clinical $\mathrm{AD}$ and mild cognitive impairment in the United States (2020-2060)," Alzheimers Dement, 2021.

[4] L. Cui, N. N. Hou, H. M. Wu et al., "Prevalence of Alzheimer's disease and Parkinson's disease in China: an updated systematical analysis," Frontiers in Aging Neuroscience, vol. 12, p. $603854,2020$.

[5] S. Wangtongkum, P. Sucharitkul, N. Silprasert, and R. Inthrachak, "Prevalence of dementia among population age over 45 years in Chiang Mai, Thailand," Journal of the Medical Association of Thailand, vol. 91, no. 11, pp. 16851690, 2008.

[6] F. M. LaFerla and K. N. Green, "Animal models of Alzheimer disease," Cold Spring Harbor Perspectives in Medicine, vol. 2, no. 11, article a006320, 2012.

[7] G. Mehlhorn, M. Hollborn, and R. Schliebs, "Induction of cytokines in glial cells surrounding cortical beta-amyloid plaques in transgenic Tg2576 mice with Alzheimer pathology," International Journal of Developmental Neuroscience, vol. 18, no. 4-5, pp. 423-431, 2000.

[8] L. F. Lue, M. N. Sabbagh, M. J. Chiu et al., "Plasma levels of A $\beta 42$ and tau identified probable Alzheimer's dementia: findings in two cohorts," Frontiers in Aging Neuroscience, vol. 9, p. 226, 2017.

[9] D. A. Butterfield and A. Castegna, "Proteomics for the identification of specifically oxidized proteins in brain: technology and application to the study of neurodegenerative disorders," Amino Acids, vol. 25, no. 3-4, pp. 419-425, 2003.

[10] N. L. Anderson and N. G. Anderson, "The Human Plasma Proteome:," Molecular \& Cellular Proteomics, vol. 1, no. 11, pp. 845-867, 2002.

[11] K. K. Dey, H. Wang, M. Niu et al., "Deep undepleted human serum proteome profiling toward biomarker discovery for Alzheimer's disease," Clinical Proteomics, vol. 16, no. 1, p. 16, 2019.

[12] D. C. Frost and L. Li, "Recent advances in mass spectrometrybased glycoproteomics," Advances in Protein Chemistry and Structural Biology, vol. 95, pp. 71-123, 2014.

[13] S. Pan, R. Chen, R. Aebersold, and T. A. Brentnall, "Mass Spectrometry Based Glycoproteomics-From a Proteomics Perspective," Molecular \& Cellular Proteomics, vol. 10, no. 1, article R110.003251, 2011.

[14] Q. Zhang, C. Ma, L. S. Chin, and L. Lian, "Integrative glycoproteomics reveals protein $\mathrm{N}$-glycosylation aberrations and glyco- proteomic network alterations in Alzheimer's disease," Science Advances, vol. 6, no. 40, article eabc5802, 2020.

[15] G. M. McKhann, D. S. Knopman, H. Chertkow et al., "The diagnosis of dementia due to Alzheimer's disease: recommendations from the National Institute on Aging-Alzheimer's Association workgroups on diagnostic guidelines for Alzheimer's disease," Alzheimer's \& Dementia, vol. 7, no. 3, pp. 263-269, 2011.

[16] O. Lowry, N. Rosebrough, A. L. Farr, and R. J. Randall, "Protein measurement with the folin phenol reagent," The Journal of Biological Chemistry, vol. 193, no. 1, pp. 265-275, 1951.

[17] P. Bardou, J. Mariette, F. Escudié, C. Djemiel, and C. Klopp, "Jvenn: an interactive Venn diagram viewer," BMC Bioinformatics, vol. 15, no. 1, p. 293, 2014.

[18] R. A. Nixon, A. M. Cataldo, and P. M. Mathews, "The endosomal-lysosomal system of neurons in Alzheimer's disease pathogenesis: a review," Neurochemical Research, vol. 25, no. 9/10, pp. 1161-1172, 2000.

[19] A. Caccamo, A. Magrì, D. X. Medina et al., "mTOR regulates tau phosphorylation and degradation: implications for Alzheimer's disease and other tauopathies," Aging Cell, vol. 12, no. 3, pp. 370-380, 2013.

[20] F. Caamaño-Isorna, M. Corral, A. Montes-Martínez, and B. Takkouche, "Education and dementia: a meta-analytic study," Neuroepidemiology, vol. 26, no. 4, pp. 226-232, 2006.

[21] C. Qiu, L. Bäckman, B. Winblad, H. Agüero-Torres, and L. Fratiglioni, "The influence of education on clinically diagnosed dementia incidence and mortality data from the Kungsholmen Project," Archives of Neurology, vol. 58, no. 12, pp. 2034-2039, 2001.

[22] R. Sims, M. Hill, and J. Williams, "The multiplex model of the genetics of Alzheimer's disease," Nature Neuroscience, vol. 23, no. 3, pp. 311-322, 2020.

[23] S. Crean, A. Ward, C. J. Mercaldi et al., “Apolipoprotein E $\varepsilon 4$ prevalence in Alzheimer's disease patients varies across global populations: a systematic literature review and meta-analysis," Dementia and Geriatric Cognitive Disorders, vol. 31, no. 1, pp. 20-30, 2011.

[24] F. F. Oliveira, E. S. Chen, M. C. Smith, and P. H. F. Bertolucci, "Predictors of cognitive and functional decline in patients with Alzheimer disease dementia from Brazil," Alzheimer Disease and Associated Disorders, vol. 30, no. 3, pp. 243-250, 2016.

[25] Y. Yamazaki, N. Zhao, T. R. Caulfield, C.-C. Liu, and G. Bu, "Apolipoprotein E and Alzheimer disease: pathobiology and targeting strategies," Nature Reviews. Neurology, vol. 15, no. 9, pp. 501-518, 2019.

[26] D. C. Hondius, P. van Nierop, K. W. Li et al., "Profiling the human hippocampal proteome at all pathologic stages of Alzheimer's disease," Alzheimer's \& Dementia, vol. 12, no. 6, pp. 654-668, 2016.

[27] G. Sathe, C. H. Na, S. Renuse et al., "Quantitative proteomic profiling of cerebrospinal fluid to identify candidate biomarkers for Alzheimer's disease," Proteomics. Clinical Applications, vol. 13, no. 4, article e1800105, 2019.

[28] M. S. Gurses, M. N. Ural, M. A. Gulec, O. Akyol, and S. Akyol, "Pathophysiological function of ADAMTS enzymes on molecular mechanism of Alzheimer's disease," Aging and Disease, vol. 7, no. 4, pp. 479-490, 2016.

[29] N.-N. Yu, M.-S. Tan, J.-T. Yu, A.-M. Xie, and L. Tan, “The role of Reelin signaling in Alzheimer's disease," Molecular Neurobiology, vol. 53, no. 8, pp. 5692-5700, 2016. 
[30] D. Krstic, M. Rodriguez, and I. Knuesel, "Regulated proteolytic processing of Reelin through interplay of tissue plasminogen activator (tPA), ADAMTS-4, ADAMTS-5, and their modulators," PLoS One, vol. 7, no. 10, article e47793, 2012.

[31] A. Hisanaga, S. Morishita, K. Suzuki et al., "A disintegrin and metalloproteinase with thrombospondin motifs 4 (ADAMTS-4) cleaves Reelin in an isoform-dependent manner," FEBS Letters, vol. 586, no. 19, pp. 3349-3353, 2012.

[32] Y. Gerakis, M. Quintero, H. Li, and C. Hetz, "The UFMylation system in proteostasis and beyond," Trends in Cell Biology, vol. 29, no. 12, pp. 974-986, 2019.

[33] Y. Gerakis and C. Hetz, "Emerging roles of ER stress in the etiology and pathogenesis of Alzheimer's disease," The FEBS Journal, vol. 285, no. 6, pp. 995-1011, 2018.

[34] C. O. Hung and M. P. Coleman, "KIF1A mediates axonal transport of BACE1 and identification of independently moving cargoes in living SCG neurons," Traffic, vol. 17, no. 11, pp. 1155-1167, 2016.

[35] P. C. Kandalepas, K. R. Sadleir, W. A. Eimer, J. Zhao, D. A. Nicholson, and R. Vassar, "The Alzheimer's $\beta$-secretase BACE1 localizes to normal presynaptic terminals and to dystrophic presynaptic terminals surrounding amyloid plaques," Acta Neuropathologica, vol. 126, no. 3, pp. 329-352, 2013.

[36] J. Zhao, Y. Fu, M. Yasvoina et al., "Site Amyloid Precursor Protein Cleaving Enzyme 1 Levels Become Elevated in Neurons around Amyloid Plaques: Implications for Alzheimer's Disease Pathogenesis," The Journal of Neuroscience, vol. 27, no. 14, pp. 3639-3649, 2007.

[37] X. Zhang, T. Y. Huang, J. Yancey, H. Luo, and Y.-W. Zhang, "Role of Rab GTPases in Alzheimer's disease," ACS Chemical Neuroscience, vol. 10, no. 2, pp. 828-838, 2019.

[38] W. Scheper, J. J. Hoozemans, C. C. Hoogenraad, A. J. M. Rozemuller, P. Eikelenboom, and F. Baas, "Rab6 is increased in Alzheimer's disease brain and correlates with endoplasmic reticulum stress," Neuropathology and Applied Neurobiology, vol. 33, no. 5, pp. 523-532, 2007.

[39] L. McConlogue, F. Castellano, C. deWit, D. Schenk, and W. A. Maltese, "Differential Effects of a Rab6 Mutant on Secretory _Versus_Amyloidogenic Processing of Alzheimer's $\beta$-Amyloid Precursor Protein," The Journal of Biological Chemistry, vol. 271, no. 3, pp. 1343-1348, 1996.

[40] D. Venkateswarlu, L. Perera, T. Darden, and L. G. Pedersen, "Structure and dynamics of zymogen human blood coagulation factor X," Biophysical Journal, vol. 82, no. 3, pp. 11901206, 2002.

[41] P. Grammas, "Neurovascular dysfunction, inflammation and endothelial activation: implications for the pathogenesis of Alzheimer's disease," Journal of Neuroinflammation, vol. 8, no. 1, p. 26, 2011.

[42] D. Y. Lee, K. W. Park, and B. K. Jin, “Thrombin induces neurodegeneration and microglial activation in the cortex _in vivo_ and _in vitro_: Proteolytic and non-proteolytic actions," Biochemical and Biophysical Research Communications, vol. 346, no. 3, pp. 727-738, 2006.

[43] H. J. Jürgensen, K. Johansson, D. H. Madsen et al., "Complex Determinants in Specific Members of the Mannose Receptor Family Govern Collagen Endocytosis," The Journal of Biological Chemistry, vol. 289, no. 11, pp. 7935-7947, 2014.

[44] A. M. Cataldo, C. M. Peterhoff, J. C. Troncoso, T. Gomez-Isla, B. T. Hyman, and R. A. Nixon, "Endocytic Pathway Abnormalities Precede Amyloid $\beta$ Deposition in Sporadic
Alzheimer's Disease and Down Syndrome: Differential Effects of APOE Genotype and Presenilin Mutations," The American Journal of Pathology, vol. 157, no. 1, pp. 277-286, 2000.

[45] T. F. Galatro, I. R. Holtman, A. M. Lerario et al., "Transcriptomic analysis of purified human cortical microglia reveals ageassociated changes," Nature Neuroscience, vol. 20, no. 8, pp. 1162-1171, 2017.

[46] J. Stevenson, E. Y. Huang, and J. A. Olzmann, "Endoplasmic reticulum-associated degradation and lipid homeostasis," Annual Review of Nutrition, vol. 36, no. 1, pp. 511-542, 2016.

[47] J. P Bennett and P. M Keeney, “Micro RNA's (mirna's) may help explain expression of multiple genes in Alzheimer's Frontal Cortex," Journal of Systems and Integrative Neuroscience, vol. 3, no. 5, pp. 1-9, 2017.

[48] C. Julien, C. Tremblay, V. Émond et al., "Sirtuin 1 reduction parallels the accumulation of tau in Alzheimer disease," Journal of Neuropathology and Experimental Neurology, vol. 68, no. 1, pp. 48-58, 2009.

[49] M. Cieślik, G. A. Czapski, and J. B. Strosznajder, "The molecular mechanism of amyloid $\beta 42$ peptide toxicity: the role of sphingosine kinase-1 and mitochondrial sirtuins," PLoS One, vol. 10, no. 9, article e0137193, 2015.

[50] A. Parent, S. J. Roy, C. Iorio-Morin et al., "ANKRD13C Acts as a Molecular Chaperone for G Protein-coupled Receptors," The Journal of Biological Chemistry, vol. 285, no. 52, pp. 4083840851, 2010.

[51] J. Zhao, Y. Deng, Z. Jiang, and H. Qing, "G Protein-coupled receptors (GPCRs) in Alzheimer's disease: a focus on BACE1 related GPCRs," Frontiers in Aging Neuroscience, vol. 8, p. 58, 2016.

[52] C. Wu, X. Cui, L. Huang et al., "IRTKS promotes insulin signaling transduction through inhibiting SHIP2 phosphatase activity," International Journal of Molecular Sciences, vol. 20, no. 11, p. 2834, 2019.

[53] L. Y. Huang, Y. P. Wang, B. F. Wei et al., "Deficiency of IRTKS as an adaptor of insulin receptor leads to insulin resistance," Cell Research, vol. 23, no. 11, pp. 1310-1321, 2013.

[54] D. Kellar and S. Craft, "Brain insulin resistance in Alzheimer's disease and related disorders: mechanisms and therapeutic approaches," Lancet Neurology, vol. 19, no. 9, pp. 758-766, 2020.

[55] M. Chen and W. Xia, "Proteomic profiling of plasma and brain tissue from Alzheimer's disease patients reveals candidate network of plasma biomarkers," Journal of Alzheimer's Disease, vol. 76, no. 1, pp. 349-368, 2020.

[56] X. Z. Yuan, S. Sun, C. C. Tan, J.-T. Yu, and L. Tan, “The role of ADAM10 in Alzheimer's disease," Journal of Alzheimer's Disease, vol. 58, no. 2, pp. 303-322, 2017.

[57] M. Shinohara, M. Tachibana, T. Kanekiyo, and G. Bu, "Role of LRP1 in the pathogenesis of Alzheimer's disease: evidence from clinical and preclinical studies:," Journal of Lipid Research, vol. 58, no. 7, pp. 1267-1281, 2017.

[58] S. van Veen, S. Martin, C. van den Haute et al., "ATP13A2 deficiency disrupts lysosomal polyamine export," Nature, vol. 578, no. 7795, pp. 419-424, 2020.

[59] A. Ledonne and N. B. Mercuri, "On the modulatory roles of neuregulins/ErbB signaling on synaptic plasticity," International Journal of Molecular Sciences, vol. 21, no. 1, p. 275, 2020.

[60] D. M. A. Hermkens, O. C. G. Stam, N. M. de Wit et al., "Profiling the unique protective properties of intracranial arterial endothelial cells," Acta Neuropathologica Communications, vol. 7 , no. 1, p. 151, 2019. 
[61] A. Hye, S. Lynham, M. Thambisetty et al., "Proteome-based plasma biomarkers for Alzheimer's disease," Brain, vol. 129, no. 11, pp. 3042-3050, 2006.

[62] J. W. Erickson and R. A. Cerione, "Structural elements, mechanism, and evolutionary convergence of rho protein-guanine nucleotide exchange factor complexes," Biochemistry, vol. 43, no. 4, pp. 837-842, 2004.

[63] B. J. Aguilar, Y. Zhu, and Q. Lu, "Rho GTPases as therapeutic targets in Alzheimer's disease," Alzheimer's Research \& Therapy, vol. 9, no. 1, p. 97, 2017.

[64] M. Borin, C. Saraceno, M. Catania et al., "Racl activation links tau hyperphosphorylation and $\mathrm{A} \beta$ dysmetabolism in Alzheimer's disease," Acta Neuropathologica Communications, vol. 6, no. 1, p. 61, 2018.

[65] S. P. Braithwaite, J. B. Stock, P. J. Lombroso, and A. C. Nairn, "Protein phosphatases and Alzheimer's disease," Progress in Molecular Biology and Translational Science, vol. 106, pp. 343-379, 2012.

[66] D. R. McIlwain, T. Berger, and T. W. Mak, "Caspase functions in cell death and disease," Cold Spring Harbor Perspectives in Biology, vol. 5, no. 4, article a008656, 2013.

[67] J. Rehker, J. Rodhe, R. R. Nesbitt et al., "Caspase-8, association with Alzheimer's disease and functional analysis of rare variants," PLoS One, vol. 12, no. 10, article e0185777, 2017.

[68] E. W. Lee, J. Seo, M. Jeong, S. Lee, and J. Song, "The roles of FADD in extrinsic apoptosis and necroptosis," BMB Reports, vol. 45, no. 9, pp. 496-508, 2012.

[69] C. K. Wu, L. Thal, D. Pizzo, L. Hansen, E. Masliah, and C. Geula, "Apoptotic signals within the basal forebrain cholinergic neurons in Alzheimer's disease," Experimental Neurology, vol. 195, no. 2, pp. 484-496, 2005.

[70] O. Maier, R. Fischer, C. Agresti, and K. Pfizenmaier, "TNF receptor 2 protects oligodendrocyte progenitor cells against oxidative stress," Biochemical and Biophysical Research Communications, vol. 440, no. 2, pp. 336-341, 2013.

[71] H. Jiang, P. He, J. Xie, M. Staufenbiel, R. Li, and Y. Shen, "Genetic deletion of TNFRII gene enhances the Alzheimerlike pathology in an APP transgenic mouse model via reduction of phosphorylated $\mathrm{I} \kappa \mathrm{B} \alpha$," Human Molecular Genetics, vol. 23, no. 18, pp. 4906-4918, 2014.

[72] R. Sewduth, B. Jaspard-Vinassa, C. Peghaire et al., "The ubiquitin ligase PDZRN3 is required for vascular morphogenesis through Wnt/planar cell polarity signalling," Nature Communications, vol. 5, no. 1, p. 4832, 2014.

[73] L. D. Harris, S. Jasem, and J. D. F. Licchesi, "The ubiquitin system in Alzheimer's disease," Advances in Experimental Medicine and Biology, vol. 1233, pp. 195-221, 2020.

[74] A. L. Gavin, D. Huang, C. Huber et al., "PLD3 and PLD4 are single-stranded acid exonucleases that regulate endosomal nucleic-acid sensing," Nature Immunology, vol. 19, no. 9, pp. 942-953, 2018.

[75] H. Scholtzova, R. J. Kascsak, K. A. Bates et al., "Induction of toll-like receptor 9 signaling as a method for ameliorating Alzheimer's disease-related pathology," The Journal of Neuroscience, vol. 29, no. 6, pp. 1846-1854, 2009.

[76] P. C. Stirling, J. Cuéllar, G. A. Alfaro et al., "PhLP3 Modulates CCT-mediated Actin and Tubulin Folding via Ternary Complexes with Substrates," The Journal of Biological Chemistry, vol. 281, no. 11, pp. 7012-7021, 2006.
[77] E. Schuller, T. Gulesserian, R. Seidl, N. Cairns, and G. Lubec, "Brain t-complex polypeptide 1 (TCP-1) related to its natural substrate $\beta 1$ tubulin is decreased in Alzheimer's disease," Life Sciences, vol. 69, no. 3, pp. 263-270, 2001.

[78] E. S. Sharp and M. Gatz, "Relationship between education and dementia: an updated systematic review," Alzheimer Disease and Associated Disorders, vol. 25, no. 4, pp. 289304, 2011. 